\title{
Los "socialismos reales" hacen su propia autocrítica y redescubren su historia
}

\author{
Francisco J. Ibisate
}

\section{Resumen}

¿El socialismo está muerto y sepultado? Este artículo recoge las memorias de los socialismos reales para aprender de la historia, convencido de que el olvido y el silencio no resuelven los problemas. Entonces, ¿cómo recoger en la forma más objetiva las memorias de los socialismos reales y cómo contribuir universitariamente a la glasnot, a decir la verdad? ¿Cómo utilizar estas reflexiones de manera que nos sirvan a hacer nuestra historia? De esta experiencia, El Salvador tiene mucho que aprender, pues lo que los socialismos hagan o no hagan nos puede orientar a nosotros que caminamos sobre la misma órbita internacional.

El pasado año me obsequiaron una caja de plástico conteniendo unas piedras del muro de Berlín, un recuerdo que se llevan todos los turistas de las Alemanias unificadas. He mirado muchas veces este souvenir y me he preguntado si ese cúmulo de piedras es un adiós o un requiem a las economías del este: ¿el socialismo está muerto y sepultado? Después pensé que también el mismo Berlín, Colonia, Dresde..., Hiroshima y Nagasaki habían sido destruidas sin dejar piedra sobre piedra. Pasado el tiempo, de las cenizas se han reconstruído dos grandes naciones, dos primeras potencias, que son como una enciclopedia moderna de aprendizaje técnico-económico. ¿No podría realizarse algo semejante con los residuos del muro de Berlín, una reencarnación económica? Ob- viamente, no deseo que se vuelva a levantar un muro que divide, erizado de ametralladoras y rodeado de campos minados, porque de divisionismos, bombas y guerras ya hemos tenido demasiado en el siglo que termina.

Han fracasado determinadas formas o modelos, llamados "socialismos reales" para significar que han sido "irreales". Pero hay algo que continúa: la auto-crítica y la revisión de su historia, para no volver a repetir la misma historia, las mismas contradicciones internas que los han llevado a lo que unos califican de crisis, otros como fracaso, otros dicen derrumbe, $y$ algunos prefieren hablar de "muerto y sepultado".

En cualquiera de los supuestos y ya que es 
costumbre hacer el panegírico hasta de los mismos muertos, ¿por qué no recoger las memorias, bajo forma de autocritica, de los supervivientes de estos modelos económicos? Tampoco es tarea fácil hacer las memorias de los socialismos reales, por la sencilla razón de que las memorias son diferentes, incluso contradictorias, como lo percibimos en los controvertidos tirones que experimenta la fase de la post-perestroika. Pero, no por ello podemos renunciar a hacer sus memorias, porque la historia es la maestra de la vida. Mal hacen quienes, por un triunfalismo ideológico, creen improcedente perder el tiempo en semejante tarea; y mal hacen quienes, sintiéndose defraudados o desfasados, prefieren cegar sus memorias, porque el olvido y el silencio no corrigen los problemas.

Llegados a este punto surge una doble pregunta: ¿cómo recoger en la forma más objetiva las memorias de los socialismos reales, y cómo contribuir universitariamente a la glasnot, a decir la verdad? ¿Cómo utilizar estas reflexiones de manera que nos sirvan a hacer nuestra historia? Sin duda el método y la objetividad científica nos piden apegarnos a la evaluación y autocrítica que, tanto los intelectuales como el pueblo de esos países, vienen realizando en los últimos años. Aquí ocupan luar importante los escritos de $\mathrm{M}$. Gorbachov, entre otros, su Perestroika y el Informe al pleno del Partido de 1987.

Las reflexiones que de aquí emanen no son entretenimiento ocioso: todas estas naciones tienen que remodelarse política, económica, ideológica y socialmente para integrarse en un espacio y en un ambiente internacional relativamente desconocidos. Para ellos es una aventura semejante a los primeros viajes espaciales, donde tendrán que aclimatarse a las nuevas fuerzas de la gravedad del mercado nacional e internacional. Lo que ellos hagan o no hagan nos puede orientar a nosotros que caminamos sobre la misma órbita internacional.

\section{Problemas centrales de la historia rusa y soviética: nuevos estudios y enfoques}

El lítulo está tomado literalmente de las nuevas publicaciones editadas por la Academia de Ciencias de la Unión Soviética ${ }^{1}$. Es interesante recorrer su consejo de redacción, donde aparecen, junto a varios doctores en ciencias históricas, algunos economistas asesores cercanos de $\mathbf{M}$. Gorbachov, colaboradores en la preparación de los modelos económicos alternativos, así como dos miembros prominentes del equipo Novosibirsk o extensión siberiana de la Academia de Ciencias de la Unión Soviétivca, A. Aganbegian (su modelo económico lo mencionaremos más adelante) y $\mathrm{T}$. Zaslauskaya, presidente de la Asociación Soviética de Sociología. Por añadidura, varios de los miembros del consejo de redacción pertenecen al nuevo movimiento (¿partido?) Unión Democrática de la URSS. Esta composición del consejo de redacción da una mayor confianza en la objetividad crítica de toda esta arqueología histórica.

Por supuesto, la intención y alcance de este artículo no es resumir las quince publicaciones de esta serie histórica, porque uno de los problemas que se plantean estos mismos autores es cómo redescubrir su historia, una historia donde han quedado tantas lagunas, tantos puntos suspensivos, tantos documentos ocultos a la luz pública, tanta tergiversación oficial, y por qué no decirlo con ellos, tanto dogmatismos, tanto engaño y autoengaño. He ahí la necesidad de la glasnot, decir la verdad. Y esta es una primera reflexión: en el este y en el oeste con cuanta frecuencia se oculta la verdad. En estas tácticas los contrarios se juntan.

Ya antes de 1990, una serie de encuentros y foros internacionales (Barcelona, 1988; Moscú, 1989; La Sorbona, 1990...) han sido lugares y tiempos propicios para dejar emanar, desde las diversas especialidades, la evaluación y crítica en los aspectos políticos, económicos, ideológicos y culturales, con una franca y objetiva sinceridad. La prensa europea ha seguido semana a semana, por no decir día a día, los acontecimientos y las controversias del este. Por lo que toca a los análisis de la situación y remodelación económica, entre los múltiples estudios, merece la pena destacar el diagnóstico y las recomendaciones redactados en Washington, previa consultoria a diversas oficinas soviéticas, por delegados de las principales instituciones financieras internacionales ${ }^{2}$. Todas estas instituciones multinacionales están preocupadas por el derrumbe económico de las 


\section{En el este y en el oeste con cuánta frecuencia se oculta la verdad. En estas tácticas los contrarios se juntan.}

economías del este y sus repercusiones internacionales; por ello, están interesadas en su remodelación y readecuación en el marco mundial.

A fin de estructurar este amplio material, parte pequeña del ya existente, parece oportuno apegarse al orden temático seguido en los citados foros de Barcelona, Moscú y La Sorbona-París: análisis de los aspectos políticos, la situación y los problemas económicos, y el papel de la cultura en un sentido amplio, como libertad de expresión.

\subsection{El revisionismo político: la crítica al cen- tralismo}

El término "centralismo" integra diversas capas y ramificaciones múltiples que amarran las esferas políticas, económicas, culturales y también el área geográfica. El calificativo de regímenes totalmente centralizados define una característica congénita del modelo y, en consecuencia, del estallido final del modelo.

\subsubsection{La intolerancia del imperio: la década de} 1980...

El imperio se hace la perestroika. Yendo del presente hacia el pasado, ahí está como punto de agenda candente, el problema de las nacionalidades en la Unión Soviética, y ahí está la guerra civil en la Yugoslavia de Tito. La controversia se tipifica ahora en el capitulo final que cierre los enfrentamientos o los arreglos entre B. Yeltsin y M. Gorbachov. El hecho de que las siglas de la URSS se lean "Unión de Repúblicas Soberanas Soviéticas" es una respuesta legal a lo que se ha venido llamando el dilema de "la des-unión soviética". Pero el problema de las nacionalidades no tiene una simple dimensión legal o jurídica, por muy importante que esto sea, sino que repercute en todo el ordenamiento y la reestructuración económica.

No puede procederse a la reorganización económica mientras no se legalicen las autonomías regionales y los poderes centrales. Por citar algunos ejemplos: cuáles serán las funciones del Ban- co Central de la Unión (Gosbank) y cuáles las funciones de los cien bancos republicanos. ¿Cómo se reestructura la autoridad monetaria central y las republicanas para conjugar las políticas monetarias internas, el control de la moneda nacional y regional, y muy particularmente, el tipo de cambio real del rublo que, de transferible, tiene que pasar a ser convertible? ¿Cuál va a ser la soberanía fiscal de los gobiemos republicanos y cuál la fuente de ingresos del gobierno central? ¿Qué precios y qué sectores estratégicos quedan supeditados al control central y cuáles quedan sometidos a la libre determinación de las repúblicas y del mercado? ¿Cómo se reorganiza el entorpecido sistema comercial interrepublicano e internacional una vez que se pone fin al monopolio ministerial-financiero del comercio exterior?

Estos y otros puntos plantean un problema, no de retro, sino de frenoalimentación, entre la esfera política y la económica. La perestroika económica no puede implementarse mientras no se fijen las fronteras del poder de la federación y de las repúblicas. Pero la misma reestructuración política se encuentra trabada por las dificultades reales económicas y por las resistencias ideológicas, digamos dogmáticas, a los cambios políticos y económicos. Los Suslov y Ligachov siguen defendiendo los dogmas y el imperialismo del centro.

La pregunta lógica es ¿cómo nace el centralismo y la resistencia al centralismo? La reacción al centralismo no sólo se ha dado al interior de la Unión Soviética, como problema de las nacionalidades, sino al interior del bloque socialista, llegando incluso a la disolución del Pacto de Varsovia y a un necesario reordenamiento de la Comisión de Mutua Ayuda Económica (CAEM). De esta manera se pone fin a la práctica de la teoría de la "coexistencia pacífica", que, aplicada a las economías del bloque-este, se fundaba en el doble principio: la solidaridad internacional bajo la hegemonía del Estado más poderoso y patria de la revolución socialista mundial (art. 28 de la Constitución soviética), y el principio de la "soberanía limitada" de cada nación satélite. En virtud de este 
principio, se legitimó la intervención de las tropas del Pacto de Varsovia y de los tanques soviéticos en Checoslovaquia (1968) y luego en Afganistán (1979)...

Es claro que con $M$. Gorbachov se inicia un cambio tal como se aprecia en el texto de la "Declaración soviético-yugoslava" del 18 de marzo de 1988. "Yugoslavia y la URSS confirman su disposición a desarrollar y enriquecer sustancialmente sus relaciones desde el principio de independencia, igualdad y no ingerencia; la responsabilidad de cada partido a la clase obrera y al pueblo de su propio país; el respeto a los diferentes caminos de construir el socialismo y establecer sus posiciones internacionales". En esas mismas fechas se estaban realizando las investigaciones de los autores intelectuales de la invasión a Checoslovaquia, así como la rehabilitación de reformadores exilados.

\section{(a) La década de 1955-1965: Khrutchev}

Sin embargo, la reacción e intolerancia del centralismo sobrepasa los treinta y cinco años de existencia sumisa; nos acercamos así a uno de los puntos claves de la historiografía soviética y socialista, cual es todo el proceso de desestalinización. Luego de la muerte de Estalin, N. Khrutchev, quien por primera vez critica rudamente el período terrorista de su predecesor en el $\mathrm{XX}^{2}$ Congreso del Partido (1956), inicia todo un proceso de remodelación en la Unión Soviética. El nuevo ensayo busca restar el mayor poder a la burocracia central, que durante treinta años había controlado hasta los mínimos detalles de la producción, transfiriendo el control y la supervisión económica a las repúblicas y regiones, creando los comités económicos regionales (sovnarjozhes). Se llevó a cabo un proceso de "deconcentración-económica", que hubo que cortar y corregir a los siete años. ¿Qué estaba sucediendo? Con el proceso de deconcentración de poderes surge, de 1955 a 1962 , el espíritu republicano y regional o nacionalista. En ese interludio, cada república, región y nacionalidad se concentra en su propio auge y crecimiento, resquebrajando todo el mosaico de la unión. La centralización se traduce en descentralización, y se hace presente el primer aviso del piloto rojo.
El problema era más serio, porque Yugoslavia (Tito) se independiza del bloque en 1950, y a las convulsiones nacionales de Hungria, Polonia, Checoslovaquia (1955...) se responde con la invasión sangrienta de Hungria. Poco después se inicia el enfriamiento de las relaciones chino-soviéticas. A mediados de la década de 1950 , ya aflora la resistencia al centralismo, dentro y fuera de la Unión Soviética, el centralismo que controla todas las esferas de la política, del derecho, de la economía, de la ideología monolítica, todo ello fundamentado en el "culto a la personalidad" de Estalin.

Sin embargo, la explicación última no puede asentarse o resumirse en una sola persona, por usurpadora del poder que haya sido, puesto que, desaparecida la persona concreta, persevera el culto a la personalidad, y con un tiempo de espera se vuelve a reforzar el centralismo. Llegados a este punto se bifurca el hilo de la explicación que extiende sus filamentos tanto hacia las décadas precedentes como a las subsiguientes, hasta el día de hoy. Como esta segunda línea de bifurcación la trataremos más adelante, baste decir de momento que, ante las dificultades económicas y las improvisaciones gestadas por N. Khrutchev (Perestroi$k a$, pp. 46-47), se relanza todo un proceso de descentralización económica, en la Unión Soviética y en el bloque socialista, conocida como la reforma Liberman (1965).

La descentralización económica supuso una seria transformación de la esfera o mecanismo de funcionamiento económico, oficialmente aprobada, pero sin retocar la superestructura política. Razón por la cual la reforma no pasa de ser un ensayo del cual apenas quedan rastros en 1970. El nombre de Evsei Liberman ni siquiera aparece en Perestroika, y en la primavera de 1983 muere, como dice una revista inglesa, alone and forgotten.

Con la misma inspiración se inicia la Primavera de Praga, 1968, en Checoslovaquia, con reformadores como Dubcek, Ota Sik... ${ }^{3}$, y en agosto del mismo año, los tanques soviéticos tronchan otra experiencia de socialismo con rostro humano. A partir de ese momento, se vuelve a imponer el diktat de la burocracia, convertida ya en gerontocracia, entrando en la era del estancamiento Bresnev, calificada como la era del culto sin 
personalidad4.

Mediada la década de 1980 , se abre la era de la tercera o cuarta perestroika, ahora con M. Gorbachov (¿la personalidad sin culto?), precedida, desde 1979, por la vía china al socialismo: reforma (gaige) y apertura (kaigang) pretenden marcar una sensible reforma de las estructuras políticas y económicas, lidereada por el tres veces marginado y tres veces rehabilitado Deng Xiaoping. Pero no queda nada claro el porvenir de esta reforma política china a raíz de los lamentables sucesos de la plaza de Tianamen.

(b) La Academia de Ciencias de la URSS rehace la historia: la década de 1930: el fenómeno del estalinismo

Caminando río arriba, hacia la década de 1930 , nos detenemos con cierta pausa obligada ante un tema donde académicos de todas las disciplinas se han dedicado a hacer verdadera arqueología histórica. Decimos pausa obligada porque las anteriores publicaciones preparadas para la exportación, bajo el nombre de manuales de economía política o curso de economía superior de la misma Academia de Ciencias de Moscú, falseaban históricamente la verdadera realidad. En junio de 1988, la revista Voprosi istorii (Cuestiones de historia) convocó a una mesa redonda cuyo tema era, "La Unión Soviética en los affos 30". El contenido de estas ponencias se integra en la serie histórica real del estalinismo como fenómeno de la sociedad soviética. Si los mismos historiadores soviéticos están desbrozando el camino plagado de lagunas y tergiversaciones, no hay lugar aquí más que para recoger los grandes rasgos y juicios de valor sobre "La revolución estaliniana desde arriba".

Uno de los indicios es la tipología utilizada en recientes publicaciones soviéticas al decribir el modelo estalinista como "socialismo estalinista, fase primaria del socialismo, socialismo temprano, sistema administrativo, sistema administrativo de ordeno y mando, socialismo de cuartel, socialismo de Estado, socialismo autoritario-monopolista, comunismo de cuartel, comunismo grosero"... Comenta E. Plimak: "tenemos aquí una decena de definiciones y existen otras más. En el futuro veremos cuáles de éstas serán admitidas por la literatura"s. Los títulos de estas publicaciones algo dicen de las características del fenómeno estalinista, al igual que los títulos con que los participantes de la mesa redonda encabezan sus ponencias: "Singularidad de la revolución estaliniana desde arriba" (E. Plimak); "¿Existió el socialismo en los años 30?" (R. Medvédev); "Un decenio fatal" (V. Danilov); "Orígenes del triunfo y del fracaso" (V. Kulish)...

Dentro de la historiografía soviética, un documento guía para interpretar el fenómeno Estalin, documento citado por todos estos historiadores, es el Testamento de Lenín, escrito en diciembre de 1922, con un postcriptum de enero de 1923. "Lenín proponía aquí claramente la deposición de 
Estalin del cargo de Secretario General del Partido Comunista, caracterizándolo como rudo, y sugiriendo su sustitución por alguien más paciente, más leal, más gentil y atento con los camaradas, menos caprichoso. En el testamento original, Lenín ya había atacado a Estalin, advirtiendo que como secretario había concentrado un enorme poder en sus manos... y no estoy seguro de que sepa utilizar siempre ese poder con suficiente precaución"×. El testamento de Lenín quedo oculto en los infiernos de las bibliotecas y no se le dio plena lectura hasta 1956. En el mismo testamento, Lenín expresaba sus juicios sobre los líderes del partido, Zinoviev, Kamenev, Pitakov y Bukharin, calificado como el hijo predilecto de Lenín. Todos estos personajes fueron procesados y fusilados por Estalin en las purgas de los años 1935-1937. Estos son indicios bastante significativos.

Con estos antecedentes y consecuentes surge un nuevo interrogante en la actual historia soviética, donde cohabitan tres posiciones o tres imágenes algo diferentes del dictador, que ayudan a interpretar las controversias de la post-perestroika. "Los críticos del estalinismo, censurando los crímenes perpetrados por Estalin y el abandono de los legados de Lenín, estiman que el socialismo se construía en la URSS, no gracias a Estalin, sino a despecho de su voluntad. Los críticos más moderados del estalinismo sostienen, sin negar los aspectos macabros del régimen estalinista, que es imposible desligar la personalidad de Estalin de las conquistas en la edificación socialista ni de nuestros triunfos militares y diplomáticos. Los defensores del estalinismo reconocen - si no lo hacen públicamente, lo guardan en el fondo de su alma - que Estalin era un gran líder cuyo nombre, por cierto, está manchado por represiones injustificadas"...

Ante el tríptico de posturas, E. Plimak explica su punto de vista. "En mi libro, Testamento politico de V. I. Lenín: sus origenes, esencia y cumplimiento (Moscú 1988, en ruso), me inclino por la segunda postura. No obstante, existen elementos que nos permiten examinar más atentamente la primera postura y el fenómeno del estalinismo, que lo ponen al margen del socialismo en tanto figura política. Lenín se percató de los rasgos principales del incipiente estalinismo: la ambición de un poder ilimitado y la falta de suficiente prudencia en la utilización de ese poder. Producto del desarrollo histórico, el primer rasgo se tradujo en un régimen político dictatorial, similar al bonapartista; el segundo se trocó en millones de víctimas de las represiones y los errores de Estalin".

La importancia histórica del tema, y no una malsana curiosidad, exigen una acumulación de testimonios sobre detalles históricos antes camuflados al público nacional e internacional. El Archipiélago Gulag y otras obras prohibidas habían comenzado a levantar el tapete que ahora se descorre con mayor flexibilidad. Por ello, seguimos escuchando de momento al mismo E. Plimak. "Los crimenes cometidos por Estalin entre 19371939 no tienen justificación histórica alguna. Tras un período de medidas de emergencia, se presentó la posibilidad de normalizar y democratizar la vida en el país. En este contexto, Estalin creó una situación artificial, de emergencia, aprovechando el asesinato de Kirov. Este asesinato -fuese inspirado por Estalin o sólo fuese un pretexto para él- trajo como consecuencia represiones masivas contra intelectuales y militantes del partido con el fin de consolidar y preservar el régimen de poder personal, que carecía para serlo de fundamento objetivo".

"Para ello sirvieron, asimismo, las tradiciones de lucha contra el trostkismo, convertido en espantajo macabro, en un instrumento para convertir a los adeptos en enemigos, en un pararrayo para justificar los crimenes del estalinismo. El país vivió una atmósfera de idolatría ante el líder; quedó paralizada la vida política; la economía nacional se vio en muchos aspectos desorganizada y la capacidad defensiva resultó socavada. La cultura entró en un período de estancamiento. Todos estos factores se hicieron sentir fuertemente en la primera etapa de la Gran Guerra Patria (1940...) y obligaron a sacrificar 20 millones de vidas más, aparte de los 7 ó 12 millones de víctimas inmoladas en los años anteriores".

"Nos olvidamos de que las formas ilusorias, casi religiosas de conciencia, originaron el entusiasmo y el culto al líder, tanto más que los crímenes cometidos por las autoridades o bien eran 
ocultados a la opinión pública, o camuflados con postulados del marxismo deformado y datos falsificados por el Comisariato del Pueblo de Asuntos Interiores (N.K.V.D.). Tal fue el precio que se debió pagar por el incumplimiento del testamento de Lenin. La edificación del socialismo no podía evitar las víctimas, pero Estalin cuadriplicó su número. A él le presentamos hoy la cuenta de graves acusaciones. El XX ${ }^{9}$ Congreso del Partido (Khrutchev, 1956) abrió esa cuenta, y ahora profundizamos su línea. Se trata no sólo de luchar contra los rasgos más odiosos del estalinismo - las presiones y el culto a la personalidad - sino de demoler sus pilares, o sea, el sistema administrativo de ordeno y mando, implantado por Estalin"?

Sería posible seguir emborronando páginas en blanco con testimonios del mismo autor y de otros autores. El lector, ávido de más detalles - por simpatía o antipatía a estos socialismos realespuede recurrir a la bibliografía aquí citada. Entre los historiadores soviéticos se citan los nombres de Yuri Afasaniev, director del Instituto de Archivos Históricos, quien participara en el foro de Moscú ${ }^{8}$. El otro autor es Roy Medvédev, ponente en la presente mesa redonda y quien ha escrito una documentada biografía de Estalin: "Que la historia juzgue: los origenes y las consecuencias del estalinismo". De las novecientas páginas de esta obra, diríamos que las dos terceras partes están teñidas de rojo, describiendo las purgas que se van sucediendo contra los líderes del partido afines a Lenín, los grandes economistas que forjaron los primeros planes quinquenales, luego los mejores ingenieros acusados de sabotaje, los hombres de la cultura, y la purga de más de $40 \mathrm{mil}$ altos generales y oficiales del ejército rojo en vísperas de iniciarse la segunda guerra mundial, para terminar con las purgas de postguerra hasta el momento en que llegara a desconfiar de sus más allegados miembros de la nomenklatur $a^{10}$. Por supuesto, esta política del terror es el carrefour donde se entrecruzan todos los participantes en esta mesa redonda de Moscú, en 1988. Ante este escenario surge la pregunta: ¿cómo se pudo ir creando el culto y la idolatría al líder o cómo se puede hablar de socialismo estalinista?

\subsubsection{El culto a la personalidad y la estructu- ración económica}

Para captar mejor el sentido de algunas referencias económicas hechas por este grupo de historiadores se introduce un pequeño interludio aclaratorio. En la década de 1920, con ocasión de la llamada Nueva Política Económica (NEP) de Lenín, tienen lugar dos importantes discusiones entre renombrados economistas de la época. En primer lugar, un grupo de economistas (Kondratieff, Groman, Bazarov...) defiende ya en ese entonces que en el socialismo se debían integrar el plan y el mercado, de manera que éste último sirviera de orientación y de control al plan ${ }^{11}$. Los nombres de estos autores aparecerán más adelante en las cincuenta primeras páginas del Archipiélago de $\mathrm{Gu}$ lag (Soljenitsin).

La segunda discusión, más afín a nuestro tema, enfrenta a los dos economistas más notorios, $\mathbf{N}$. Bukharin y E. Preobranzhensky, quienes en 1919 habian redactado juntos al Azbuka Kommumizmi ("El ABC del comunismo"). Mientras que $\mathrm{N}$. Bukharin defendía un crecimiento equilibrado de la industria y del agro a través de intercambios equivalentes (o sustancia de la ley del valor) para no poner en peligro la alianza obrero-campesina, E. Preobranzhensky defendía literalmente la "acumulación primitiva socialista", a través de intercambios de precios desiguales, de suerte que la plusvalía extraída del sector campesino se transformara en acumulación del sector industrial. La tesis de Preobranzhensky es mucho más estructurada que estas dos líneas, más razonada y aplicada a las circunstancias obrero campesinas del momento ${ }^{12}$.

Inicialmente, Estalin apoya la postura de $\mathbf{N}$. Bukharin, pero poco a poco se vuelve contra él, no tanto por razones económicas - que nunca las tuvo-, sino más bien por considerarlo el delfín predilecto de Lenín. Al mismo tiempo, se vuelve contra E. Preobrazhensy, acusado de trostkista, de alentar la ruptura entre el campo y la ciudad. Estos dos grandes economistas, hoy rehabilitados, fueron fusilados en los años 1936-1937, con ocasión de las purgas del equipo de Lenín (Zinoviev, 
Kamenez), aprovechando el asesinato de Kirov, hoy día cargado al debe o al haber de Estalin. En realidad, quien ejecutará en la forma más drástica la acumulación primitiva socialista será Estalin, con el apresurado y forzado proceso de colectivización campesina o kolkozhes.

Con este intermedio volvamos a la pregunta: ¿se puede hablar de socialismo estalinista? Intercalamos una serie de testimonios expresados en la mesa redonda de Moscú. El historiador R. Medvédev dice: "retornando al fenómeno de Estalin, debo decir que no era la consolidación, sino la usurpación del poder. Ante un interrogante directo: ¿quién era Estalin: dirigente del partido o monarca absoluto? No vacilaría en responder que era un tirano, un déspota, que ni siquiera considèró necesario limitar su poder a los marcos que restringían el poder del zar. Para Estalin no existia limitación alguna. Era un usurpador, un tirano, un déspota para con el partido, el Estado y el pueblo. Lo anterior no quiere decir que niegue lo positivo que hubo en los años 30 . Debo decir que en los años 30 se educó una joven generación muy buena, mejor que en otras décadas... Por supuesto, estos jóvenes estaban engañados, no conocían muchas cosas, pero eran en su gran mayoria gente honesta, gente de confiar, dispuesta a morir en aras de la patria... La mayoría de aquellos jóvenes perecieron, naturalmente, en los campos de batalla de la Gran Guerra Patria, pero algunos viven todavía y sus cualidades constituyen el patrimonio que hoy es aprovechado por la perestroika"13. En las páginas 40-45 de Perestroika podemos escuchar un juicio similar sobre la juventud y el pueblo de aquella época.

V. Kumianov, de la Academia de Ciencias de la Unión Soviética, luego de citar a Medvédev, añade nuevos datos y reflexiones. "Estalin se apoyó no tanto en sus secuaces, que eran sustituidos constantemente, como en el pueblo engañado por él. Víctima de una propaganda omnipotente e hipertrofiada y de constantes presiones psicológi- cas por parte del sistema administrativo-coercitivo creado por Estalin, incluso la gente honesta y decente aprendió a creer sinceramente que era el 'Lenín de hoy' y a identificar su nombre con tales conceptos sagrados como patria, padre, madre, partido, pueblo, adjudicando a Estalin todas las conquistas y logros (que a veces costaron esfuerzos sobrehumanos), todo lo bueno, humano y sabio del pueblo... Nuestra historia, con sus páginas heróicas y trágicas, es una sola. Es necesario conservar en el presente y en el futuro los elementos positivos y desechar para siempre los negativos. Los estalinistas, en cambio, tienen un propósito muy astuto, orientado a fusionar para siempre la figura de Estalin y los asuntos del partido, con el falso pretexto de que él era su Secretario General"...

"Los investigadores debemos no sólo esclarecer las lagunas de la historia, sino también rescatar, en la medida de nuestras posibilidades, sus páginas arrancadas, que en ocasiones contienen datos y hechos monstruosos. Olvidar lo malo y lo monstruoso no significa erradicarlo. Actualmente nuestra prensa está llena de publicaciones sobre Estalin, resaltando tanto su perfidia, hipocresía y crueldad como otros rasgos suyos (voluntad, decisión, consecuencia...), lo cual testimonia que él era una figura política compleja"...

"Unas pocas palabras sobre el cómo se creó el culto a la personalidad de Estalin. Se sabe que son los aduladores, embusteros y mentirosos carentes de principios, quienes se crean ídolos. Por supuesto, el mayor empeño en este sentido lo hicieron los secuaces más íntimos de Estalin: Molotov, Voroshilov, Kaganovich, Malenkov, Ezhov, Andreev, Shkiriatov, Beria, Vishinsky, Zhdanov y otros. "Alli donde la perturbación y el pánico podian en cualquier momento traducirse en la impotencia y la catástrofe, se presentaba el camarada Estalin', escribió Voroshilov en un folleto totalmente falsificado. El libro Extractos de la historia de las organizaciones del partido bolchevique en

\section{Socialismo y partido único comunista son términos contradictorios, y ahí se asienta la base de todo el dogmatismo, de toda la corrupción legal y social...}


la Transcaucasi, presuntamente escrito por Beria, estaba lleno de falsedades y adulación"14.

Una declaración más oficial sobre este tema de terror y engaño lo encontramos en las páginas 20 25 de Perestroika, con toda la autoridad que le confiere su autor, así como en la primera parte del Informe al pleno del Partido de junio de 1987. Mientras que en las páginas precedentes de $\mathrm{Pe}$ restroika y en toda la segunda parte del referido informe al partido, $M$. Gorbachov se centra en la descomposición y reestructuración del mecanismo productivo $^{15}$. La estructuración de la economía soviética, extendida también a otros países del bloque, se forjó bajo el voluntarismo de Estalin, desoyendo el parecer técnico de los mejores economistas. Con relativa brevedad, R. Medvédev esquematiza el problema.

"Ahora bien, analicemos el desarrollo individual del país. Está claro que nuestra industria ha avanzado enormemente, sobre todo la pesada y la bélica, pero era, en gran medida, una economía enferma. La vía de desarrollo económico por la que se optó en aquel entonces no estaba estructuralmente predeterminada. Es que Bukharin renunció a su concepción económica no como resultado de un análisis de la situación real de aquella época; tampoco reconoció sincera y honestamente que no tenía razón. Reconoció que Estalin tenía razón porque no tenía otra salida, o sea, su reconocimiento era forzado. Bukharin fracasó, no porque sus argumentos fueran erróneos, sino porque los métodos que utilizó en la lucha no eran enérgicos y eficaces. El primer plan quinquenal era un plan científicamente preparado por los economistas más expertos (más tarde casi todos ellos fueron ejecutados). Sólo era necesario modificar y corregir las acciones durante la ejecución del plan quinquenal. De haber sido así, la industria pesada y bélica se habrian desarrollado sobre la base de las acumulaciones reales del país, creadas en la agricultura y en la industria ligera, y no gracias a la violencia, la administración burocrática, no gracias al entusiasmo por una parte, y el miedo y las represiones por otra. Esta enorme industria progresó siempre en detrimento de la agricultura y de la industria ligera. Nunca pudimos desarrollar cabalmente la agricultura porque antes y después de la Gran Guerra Patria hubo que exprimirle todos los jugos para poder alimentar constantemente el coloso de las industrias pesadas, extractiva y bélica"16.

Por su parte, E. Plimak complementa el mismo tema. "El sistema estalinista, gracias al entusiasmo de la clase obrera, de la intelectualidad y de los activistas del partido pudo superar el atraso del país. Sin embargo, los hechos evidencian que la proporción exagerada de la acumulación (hasta 40-45 por ciento en vez del 20-30 por ciento, que era una proporción razonable) y la aceleración del desarrollo industrial provocaron graves desajustes que se dejaron sentir a finales del primer plan quinquenal, presuntamente cumplido en cuatro años y tres meses. Se ha comprobado que la colectivización obligatoria y forzada quebrantó sustancialmente, y por muchas décadas, las fuerzas productivas del campo. La violencia y la coerción rebasaron los límites tolerables. La expropiación de los kulacks se extendió a un gran número de campesinos medios y hasta pobres, tildados de secuaces de los kulacks. Se practicó una política consecuente para suprimir a los campesinos individuales como capa social. Las represiones se aplicaron a kolkhozes (cooperativas agrícolas) que incumplían los acopios de cereales, a ingenieros, dirigentes de la industria, a oficiales y generales del ejército rojo, a hombres de ciencias y artes y a activistas del partido. El total de víctimas de las represiones alcanzó, en los años de la colectivización, unos 5-10 millones de personas (datos aproximados) y 1.5-2 millones en 1937-1939, conocidos como los años del terror de Ezhov. Tales son las conclusiones y los datos estadísticos que, en rigor, son indiscutibles"17.

Resulta innecesario agregar nuevos testimonios relativos a la estructuración voluntarista de la economía, sobre lo cual vuelven los diagnósticos y las propuestas de remodelación, discutidas tanto al interior de la Unión Soviética -modelos alternativos- como en las citadas instituciones internacionales financieras. Valga recordar que la misma Universidad de Harvard, junto con el joven y sobresaliente economista soviético G. Yablinsky (o Yaulinsky) han preparado otra alternativa económica para la Unión Soviética. Hoy día está 


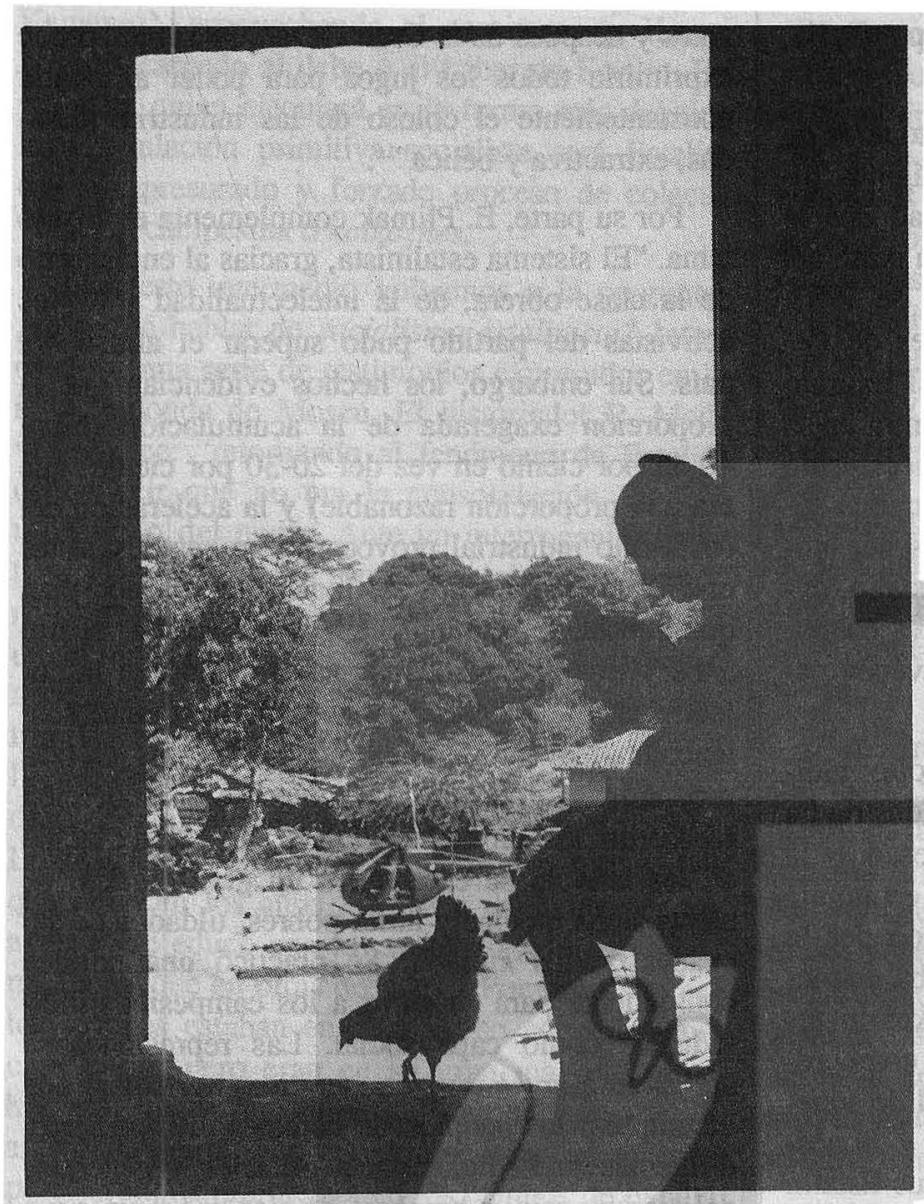

absorción del desempleo disimulado bajo la economía subterránea, ni en la fluidez comercial interrepublicana... los estalinistas, agrupados por las fuerzas militares que perderian poder y privilegios, utilizan estas resistencias económicas para adelantar el fracaso de las reformas. Esto explica que tanto en la mesa redonda de Moscú como en los foros internacionales, a que haremos mención, se vuelva y revuelva sobre las consecuencias nefastas del fenómeno estalinista en el orden político y económico. Y no se ha hecho referencia alguna a todo el desacato legal, a toda la conculcación del derecho civil y penal, hoy día agenda de urgente reforma. El equipo de Novosibirsk encendió la luz roja, y el mismo foro de Barcelona ya se centra en este tema.

En este proceso de autocrítica hay una novedad: la riada no se detiene en Estalin, sino que amaga seriamente la misma imagen (o estatua) de Lenín. El hecho de que se haya votado cambiar el nombre de Leningrado por el original de Petrogrado o San Petersburgo algo dice.

fuera de todo debate la urgente necesidad de la reestructuración radical de todo el mecanismo económico, lo que tampoco significa la plena y simple economía de mercado, como lo veremos más adelante.

Contemporáneo de la mesa redonda de Moscú fue el foro de Barcelona, donde participaron varios de los economistas e historiadores antes citados. El primer grupo de ponencias - V. Strada, F. Claudin, A. Butenko- se centran en el análisis del fenómeno estalinista ${ }^{18}$. Hay que entender, por todos los testimonios antes citados, que la resistencia de los conservadores estalinistas o de las derechas de aquellos regímenes sigue siendo fuerte. Como la misma perestroika no ha logrado todavía resultados tangibles en la disponibilidad de bienes, en el poder de compra de una moneda que dentro y fuera pierde valor continuamente, ni en la

\subsection{La intolerancia del partido único}

Sin lugar a dudas, el "no mayor" de la intolerancia se centra en la crítica y en el rechazo al partido único de vanguardia ${ }^{19}$. El problema no es que el partido comunista esté desacreditado y en decadencia, porque el 40 por ciento de sus miembros hayan desertado prácticamente de sus filas, tanto en la Unión Soviética como en los países satélites. Tampoco el problema reside propiamente, por muy intolerable que ello sea, en que la imagen del partido esté manchada con todas las atrocidades de Estalin y los suyos, los Novotny, Ceaucescu, Honecker, Bresnev... Malos recuerdos que M. Gorbachov resume así, "los principios de igualdad entre los miembros del partido eran violados frecuentemente. Muchos miembros del partido permanecieron en cargos importantes más allá del control y la crítica, lo cual condujo a fallas en 
el trabajo y a serios actos de incompetencia. En ciertos niveles administrativos surgió un desacato a la ley y se fomentó la adulación y el soborno, el servilismo y la glorificación. La gente trabajadora estaba justamente indignada ante el abuso de poder, la supresión de la crítica, las fortunas mal habidas, y en algunos casos, incluso se hizo cómplice o fue organizadora de actos criminales..."20.

Estas severas críticas, escritas y publicadas "para mi país y el mundo" por el secretario general del partido dicen mucho en pocas palabras. Tal vez haya que escucharlas como el canto del cisne, a la luz de lo que está sucediendo en la mayoría de países del bloque del este. Con todo, el tigre herido sigue lanzando zarpazos, como lo sienten casi al unísono Boris Yeltsin y M. Gorbachov.

\subsubsection{La riada llega hasta Lenín}

El verdadero cuestionamiento hoy día es si la existencia constitucional (Art. 6) de un sólo y único partido de vanguardia contradice la misma esencia del verdadero socialismo. La crítica y la intolerancia, presente y pasada, se centran en este punto: socialismo y partido único comunista son términos contradictorios, y ahí se asienta la base de todo el dogmatismo, de toda la corrupción legal y social, con todas las repercusiones en el orden o desorden económico. Muy lacónicamente lo expresa el inspirador de la primavera de Praga, Ota Sik, "el camino real para la superación, o al menos para debilitar el acceso burocrático exige la superación del monopolio leninista del Estado, que nada tiene en común con el socialismo y que está construido sobre el supuesto de una élite de poder que todo lo sabe, todo lo planifica y todo lo decide. Cuando se hayan podido modificar esos fundamentos falsamente postulados del sistema comunista y se imponga una democratización total de la economía y de la política, podrá alcanzarse una verdadera formación socialista"21. Sin duda, el rehabilitado reformador Ota Sik está viendo con agrado que su deseo o su profecía comienza a realizarse veinte años más tarde, en Checoslovaquia.

Este es punto clave por dos razones, no sólo coyunturales, sino estructurales. En primer lugar, si los socialismos reales no ponen fin al mono- polio total del partido único, nunca podrán llegar a ser reales socialismos. En segundo lugar, punto más importante, no existe ni ha existido una sola vía para acceder y ejercitar el ideal socialista. Si la vía o la línea aquí criticada, denunció al resto de iniciativas y alternativas socialistas como "socialtraidores", la historia le está devolviendo el boomerang, haciéndole la misma acusación. La transición y la elección actual es mucho más compleja que la altemativa de comunismo-capitalismo, se le llame a eso "tercera vía", o con Ota Sik, la democracia económica humana.

\section{(a) El foro de Moscú (1989)}

Estos foros son el lugar de encuentro de políticos, economistas, sociólogos, hombres de la amplia cultura del este y del oeste europeo, que analizan con sinceridad y crudeza el pasado y tienden lineamientos para el próximo futuro. Dentro del tema, la crítica se dirige contra el partido único de cuño estaliniano-brezneviano, que se resiste a cualquier perestroika. Luego, yendo del hilo al ovillo, las críticas alcanzan las bases del monumento levantado al fundador del partido, $\mathrm{V}$. I. Lenín. En la Perestroika, M. Gorbachov intenta regresar a las bases teóricas del fundador; pero dos años más tarde son esas mismas bases las que se someten a crítica, desde dentro y fuera de la Unión Soviética. Puesto que las afirmaciones conviene apoyarlas en argumentos, ojalá que los siguientes testimonios del foro de Moscú sirvan más bien para generar más interés que hastío.

Anatoli Butenko, historiador y defensor de la línea-perestroika, escribió lo siguiente, "a mí me parece que el estalinismo representaba, no un método de la construcción del socialismo, sino una tentativa bárbara de modernización del país, de acumulación primaria de recursos en la Rusia atrasada. En esa operación se formó el poder soviético, mediante la apropiación de los derechos del pueblo; y la perestroika consiste en devolver esa propiedad enajenada al pueblo y con ello el propio poder que le pertenece... Vemos, sin embargo, que en el Soviet Supremo son muy pocos los representantes del pueblo, que expresan directamente una tendencia radical para la reconquista del poder por el pueblo; y ello evidencia que la 
lucha acaba de empezar, que la perestroika no ha devuelto, y no puede devolver únicamente con la ayuda de los votos, el poder al pueblo"...

Leonid Bajtin, historiador, partidario critico de la perestroika, afirmó lo siguiente, "atravesamos una crisis profunda de la perestroika. Cuanto más brillantes son algunos informes que se dejan escuchar en el Congreso, tanto es más evidente que el Congreso y la perestroika toparon con un muro ciego: la base del totalitarismo estalinista y del neototalitarismo brezneviano fue la partitocracia de un sólo partido. En nuestro pais, por lo menos a partir de los affos veinte, nunca hubo un verdadero poder soviético, sino sólo partitocracia del partido único; es decir, el poder directo político del aparato no elegido por los veinte millones dèl partido no expresaba, ni muchos menos, los sentimientos de este ejército de militantes comunistas... Lo que hay que conseguir es que todo el poder. todo el derecho de tomar las decisiones concernientes a todo el pais, pase a los soviets elegidos sobre una base democrática"...

Yuri Afasaniev, director del Instituto de Archivos Históricos de Moscú, e historiador, sostiene que "las contradicciones que se dan en el Congreso de Diputados evidencian precisamente que además de la variante gorbachoniana de la perestroika, ya han nacido, se están formando otras variantes de la perestroika. Los problemas de procedimiento, el orden del día, todo evidencia que dar posibilidad de hablar sin restricciones a los representantes y partidarios de otro enfoque de la perestroika contradice las intenciones del aparato. La perestroika no ha comenzado todavía, y el aparato y las fuerzas vinculadas al antiguo socialismo estalinista le oponen una resistencia feroz. Por eso pienso que nos espera una etapa difícil en la lucha por crear un nuevo tipo de sociedad, renunciando al modelo estalinista de socialismo".

Yuri Kariakin, diputado del Congreso y partidario de la perestroika, dijo lo siguiente, "si los que toman las decisiones en este país escucharan lo que estamos diciendo en esta conferencia, primero, no nos entenderían, y segundo, tendrían miedo de lo que estamos diciendo. Esta sociedad que tropieza con su propia muerte no tiene otras vías de conocimiento de lo que pasa, no hay otro camino de salvación, que el de tropezar con la propia muerte; y otra vez vemos en el Congreso a diputados que se escuchan a sí mismos, porque queremos que. nos vean mejor de lo que somos. El diagnóstico también es falso aquí. El diagnóstico se percibe como la causa principal de la enfermedad. Los diputados comprenden que es preciso controlar la reforma política, porque si la perestroika supera o descarta la actual superestructura política sólo entonces será posible solucionar los problemas económicos. En definitiva, todos los planteamientos, todos los diagnósticos tropiezan, quiérase o no, en la necesidad de renovación de esa mayoría no calificada, en el Congreso y fuera del Congreso, que es la que detenta el poder"...

Paolo F. D'Arcais, historiador y director de Micromega en Italia, afirma, "me parece que la primera paradoja es que el partido comunista fue creado por Lenín con la finalidad de conquistar el poder; pero si la finalidad de la perestroika consiste en construir un Estado de derecho, es evidente que la finalidad del partido comunista debe ser devolver el poder o al menos compartirlo. Con ello tenemos que una organización, diseñada para una finalidad, debería servir hoy para prestar un servicio completamente opuesto. ¿Es esto posible? ¿Cómo se puede poner fín a la lógica de la nomenclatura, a la designación política para los puestos de responsabilidad? $\mathrm{Y}$, ¿cómo se puede plantear la cuestión de las nacionalidades, que ya se prevé en la Constitución actual, en un sentido democrático?"...

Fuera del foro de Moscú, aunque por las mismas fechas, Ota Sik añade algún nuevo matiz, a partir de la experiencia checoslovacá, en una de sus últimas publicaciones que lleva por título Hacia una democracia económica humana. En traducción casi literal, dice lo siguiente, "desde el momento en que la burocracia y la corrupción crecen dentro del partido, crece el número de mediocres e inescrupulosos en sus filas, mientras que la gente con cierta conciencia crítica se aleja de él. En la cúspide se va desarrollando una burocracia a la defensiva contra toda crítica que, en un modelo más descentralizado, pudiera venir del mercado, del sistema de precios, de la competencia empresarial. Como se sienten incompetentes se cierran 


\section{La gran alternativa u opción fundamental del mundo de hoy no se reduce a comunismo-capitalismo, plan o mercado...}

ante cualquier discusión y se refugian en medio de trabas burocráticas. Se cubren con una malentendida ortodoxia, que ellos mismos crean, condenando al mercado, a los precios y a la competencia empresarial como mecanismos antisocialistas. Deforman el propio concepto de propiedad, confundiendo la propiedad social con la propiedad siempre creciente del Estado y extraída de la plusvalf́a del trabajo. Tienen miedo a cuanto les puede hacer competencia y tienen miedo al pueblo, gracias al cual viven. Cada vez más dejan de pensar y de creer en el pueblo, y cada vez más el pueblo deja de creer en el partido"22.

El hecho de que hayan aparecido otros partidos y movimientos nacionales al interior del bloque (Solidaridad, en Polonia; Forum, en Checoslovaquia; Alianza Democrática, en Hungría; Unión Democrática, en la Unión Soviética...) significa que el partido comunista tiene que debatirse con otras agrupaciones socio-políticas, o bien tratar de camuflagearse e infiltrar otros movimientos -arte en que siguen siendo diestros- para no perder las riendas de la palestra política; se les repudia, pero se resisten a desprenderse del poder, como se aprecia en varios países satélites europeos. La batalla no está ganada, pero sí está declarada, y ello nos remonta a los albores de la revolución de octubre de 1917.

\section{(b) El foro de Barcelona (1988)}

Si en el foro de Moscú, de acuerdo al material disponible, la crítica se concentraba en el partido único de línea estaliniana o brezneviana, tanto en el foro de Barcelona (1988) como en el posterior encuentro de La Sorbona (1990), los cuestionamientos se remontan directamente hasta el fundador del partido único de vanguardia. El primer ponente, Vittorio Strada, de la Universidad de Venezia y director de la revista Rossja Rusia, se opone a la tesis que convierte a Estalin en el origen o iniciador del totalitarismo soviético. He aquí algunas líneas de su intervención.

"En este punto sería fácil unirse al coro del antiestalinismo soviético oficial y colaborar con la demonización de Estalin, transformado en un único chivo expiatorio de todos los males de Rusia y del mundo. Sería fácil, pero también sería histórica y políticamente incorrecto, porque Estalin no ha creado, sino que sólo ha potenciado el totalitarismo comunista. Fue la revolución bolchevique, la que, con su gran artífice Lenín, creó las bases de este totalitarismo, imitado luego simiescamente por los totalitarismos fascistas, tanto en oposición al liberalismo como al comunismo. Nadie niega la diferencia entre Lenín y Estalin, pero no hay operación más engañosa que la que quiere establecer una absoluta distinción político-ideológica entre ellos. No se trata de constituir una genealogía determinista que desde Marx lleve automáticamente a Lenin y de Lenín a Estalin, sino de reconocer los presupuestos políticos y las estructuras intelectuales que han actuado en la concreta complejidad del desarrollo histórico...".

"En la historia del totalismo comunista se pueden distinguir tres fases: una primera, de formación, que encuentra en Lenín a su artífice; una segunda, de pujanza, que tiene su expresión en Estalin; y una tercera, la actual, de crisis del sistema e incluso de toda la experiencia comunista. Llamo a esta fase 'totalitaria-tardía' y veo en ella las premisas para el paso a una fase post-totalitaria, paso en el que individualizó la función histórica de la Rusia-URSS, así como de la Europa democrática y el socialismo no-marxista. Sólo si este paso del totalitarismo-tardío al post-totalitarismo se realiza, Europa podrá adquirir una nueva unidad articulada y se podrá alcanzar un nuevo equilibrio mundial de manera estable...".

"En la publicitaria ideología soviética se habla hoy de 'pluralismo socialista', entendiendo con este término la tolerancia ante una multiplicidad de posiciones, si éstas respetan el ámbito del socialismo. Se trata indudablemente de cierto progreso con respecto al carácter monolítico que en la URSS ha dominado desastrosamente durante demasiadas décadas. Pero es evidente que el lími- 
te del 'socialismo' hace a este pluralismo bastante débil e incierto porque permanece intacta la autoridad que pone el límite, es decir, la que establece qué es socialismo, cuando en realidad se trata precisamente de definirlo con absoluta libertad y por lo tanto de ir más allá de él. Por ahora, sólo hay un paradójico pluralismo totalitario. El espacio vital del pluralismo es la democracia liberal, la cual puede enriquecerse, como ha ocurrido en la cultura y en la política europea, con ideas y con exigencias socialistas, pero no puede jamás renunciar a sus propios principios de libertad. El único pluralismo verdadero es el democrático, que podrá ser incluso crítico del socialismo y de sus manifestaciones concretas, pero que constituye la condición de la posibilidad de todo socialismo. 'La contradicción en la que se encuentra el totalitarismo tardío soviético está precisamente aquí: en un pluralismo socialista, que, para ser tal, debe transformarse en un pluralismo democrático, o sea post-totalitario"23.

Fernando Claudin, autor de varias obras sobre el movimiento comunista, al cual perteneciera, analiza el tema de la "revolución prematura", impulsada por Lenín, contra el parecer de otros dirigentes bolcheviques. Desde esta perspectiva, apoyado en los razonamientos de los más cercanos compañeros de Lenín, critica al fundador del partido minoritario de vanguardia. "Esta oposición también estuvo encabezada por Kamenev, acompañado por otros relevantes miembros del comité central y del gobiemo, que dimitieron de sus puestos en protesta contra la negativa de Lenín a formar la coalición. Al dimitir hicieron una declaración que resultaría profética: opinamos -decían- que resulta indispensable formar el gobierno soviético con la participación de todos los partidos soviéticos. Consideramos que fuera de este camino no existe más que una salida: mantener un gobierno bolchevique por medio del terror político. Y, en efecto asi fue. No podía ser de otra manera porque el partido bolchevique sólo representaba a una minoría... sólo obtuvo el 25 por ciento de los votos, mientras que el partido socialrevolucionario conseguía más del 50 por ciento. La disolución de la constituyente fue el golpe final a la primera y única democracia de la his- toria rusa y soviética, y liquidó la posibilidad de un compromiso entre los partidos socialistas".

"Este acto, condenado por Rosa Luxemburg y por otros eminentes marxistas de la época, no fue una simple medida coyuntural para conservar dictatorialmente el poder, sino la expresión de una estrategia de largo alcance, que ponía por encima de cualquier otra consideración el monopolio del poder... Toda esta línea fue justificada ideológicamente por el repudio a la democracia formal, calificada de burguesa, en nombre de una democracia superior, la democracia soviética. Pero en realidad fue acompanada —como había pronosticado Rosa Luxemburg: 'sin elecciones generales, sin una libertad de prensa y de reunión ilimitada, sin una lucha de opinión libre, la vida se marchita en todas las instituciones públicas, vegeta, y la burocracia queda como único elemento activo'. Palabras que merecerían ser inscritas en el frontispicio de la perestroika".

"No es fácil encontrar hitos cruciales de la historia en los que una personalidad haya desempeñado papel tan decisivo como Lenín. Y, parece bastante evidente que para Lenín - no sólo su acción, sino su obra teórica lo demuestran-, la democracia no era un valor esencial del socialismo. Sólo la valoraba como una vía posible de acumulación de fuerzas para instaurar la dictadura del proletariado o de los soviets, que en definitiva sólo eran formas simbólicas de la dictadura del partido, ungido por la ciencia y por la historia para ser el sujeto demiúrgico de la gran transformación social. Pero, ¿qué queda de esta grandiosa construcción ideológica? La experiencia de setenta años de partido único ¿no demuestra que sin la intervención real de la sociedad en la vida política, sin plena libertad para todas las tendencias políticas y que todas las ideas se manifiesten sólo queda el reino de la burocracia?"24.

Sin duda, hemos pecado por una larga acumulación de textos y testimonios literales que pueden, quizás, aburrir al lector. Sin embargo, una cierta dosis de citas literales era necesaria para entender la problemática o tirantez política en que se debaten estas economías del este. No podemos reducir todo el proceso de transición a una simple 


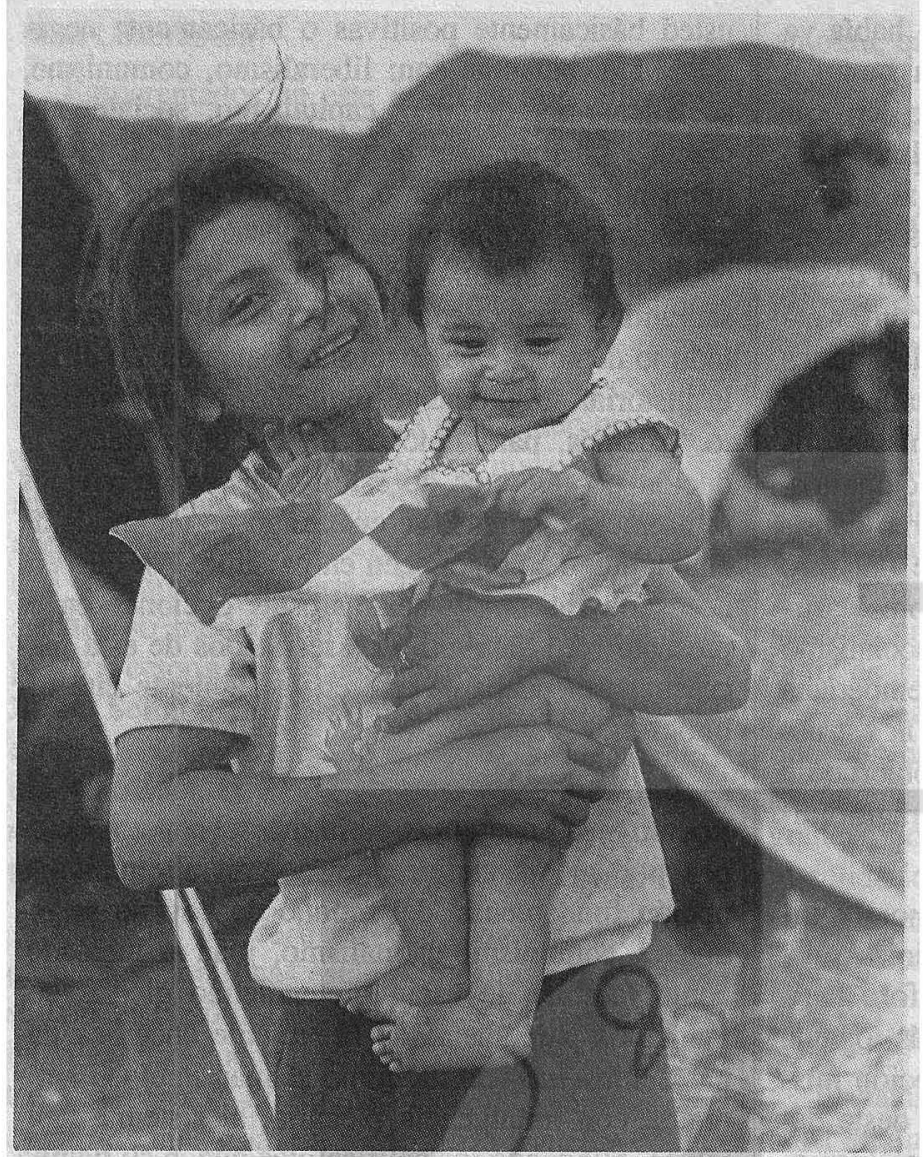

como liberalismo, comunismo, capitalismo, socialismo-democrático, social-democracia..., que a lo largo del siglo habian mantenido una coexistencia agitada. Por de pronto, la encuesta aclara que no se trata de una elección entre los extremos del espectro: comunismo-capitalismo. La realidad histórica, al igual que la televisión, no hay que mirarla en blanco y negro, sino como una gama de colores, diferenciados sí, pero no tan contradictorios los unos de los otros, desde el momento que había teorias y hechos de convergencia entre los sistemas económicos.

Sin embargo, las posibles convergencias no habian disipado los enfrentamientos y mutuas acusaciones dentro del mismo tronco común de los movimientos socialistas. En el foro de La Sorbona vuelve a aflorar esta discusión secular, es decir, del siglo $\mathbf{X X}$, con el correspondiente juicio o rendimiento de cuentas. Recordemos con G. D. H. Cole un tramo de la historia, donde se inician las turbulencias intrasocialistas. "La Segunda Internacional, que se pro-

sustitución del pasado mecanismo económico por otro más eficiente de mercado. Setenta años en otras infra y superestructuras dejan raices profundas difíciles de cambiar en el corto plazo. Además, no se trata sólo de los "socialismos reales" del este europeo, sino de remontarnos a la coexistencia de otras vías y altemativas más socialistas que tienen larga vida en el resto de Europa.

(c) El foro de La Sorbona (1990): los precursores del socialismo

A medida que nos acercamos a fechas más recientes, nos acercamos también a los prodromos o precursores del socialismo. En el foro de La Sorbona (febrero de 1990) se discute, se aclara y, en parte, se corrigen ciertos resultados que parecían emanar de la macroencuesta europea, pasada en ocho países del este y del oeste. La encuesta sondeaba la opinión frente a palabras o términos longó desde 1889 hasta su colapso en agosto de 1914, sostuvo, a pesar de los agudos conflictos de política que surgieron en su seno, una concepción del socialismo como fuerza mundial fundamentalmente unificada. Esta unidad, rota en 1914, en el terreno de la organización, desapareció del cámpo del pensamiento y de la acción como consecuencia de la revolución bolchevique en Rusia y del surgimiento del comunismo con su doctrina de la revolución mundial al estilo ruso. Porque el comunismo de la Tercera Internacional a partir de 1919 implicaba un deliberado intento, de alcance mundial, de dividir a los movimientos socialistas y obreros de todos los países en facciones agudamente opuestas en lucha por la adhesión de los trabajadores y condujo a la coexistencia no sólo de partidos rivales, comunistas y laboristas o socialistas, sino de movimientos sindicales opuestos y a perpetuos conflictos dentro de los sindicatos 
de cada país. En estas circunstancias no había ya la sombra de un movimiento socialista mundial único animado por el propósito común de derrocar al capitalismo e implantar en su lugar al socialismo. En vez de unificarse para destruir al capitalismo, los movimientos socialistas rivales se dedicaron a pelear entre sí, y los que intentaron destacar lo que había en común entre ellos, con la esperanza de reunificarlos, vieron en todas partes contrariados sus esfuerzos por los fanáticos de ambos lados. En opinión de los comunistas, los reformistas y los desviacionistas revolucionarios, -es decir, los llamados trostkystas - eran calificados de 'socialtraidores', mientras que del otro lado la mayoría de los llamados 'traidores' afirmaba abiertamente que no podía hacer socialismo sin 'democracia', - entendiendo por democracia el gobierno parlamentario- basado en la estructura de partidos contendientes y en el gobierno de la mayoría dentro de condiciones de sufragio universal y elecciones libres"25.

Con esta prelectura entendemos mejor la intervención de Michel Rocard, primer ministro del gobiemo anfitrión de Mitterand, en el foro parisino. "Los comunistas en el oeste, y más todavía en el este, quisieron apropiarse de la noción misma de socialismo; aunque lo que en el oeste denominamos socialismo quiere decir socialdemocracia, sociedad pluralista, economía competitiva y diversificada, protección social; y lo que se presentaba en el este como socialismo significa para nosotros comunismo. Es pues importante establecer la veracidad de las palabras... Desde el golpe de Estado bolchevique, los principales dirigentes de la Segunda Internacional, León Blum, Karl Kaustky y tantos otros dijeron lo esencial: que el voluntarismo de Lenín sólo podía conducir a una dictadura duradera sobre el proletariado; que sólo la democracia política permite conocer la voluntad popular; que la democracia no puede ser sólo un medio, sino un fin. La oposición que de ahí derivó entre el comunismo y el socialismo fue irreductible en el fondo ${ }^{26 "}$.

Estas intervenciones del foro de París tienen por telón de fondo la citada macroencuesta europea. Una de las preguntas decía: "Dígame si cada una de las palabras que le voy a citar son para usted básicamente positivas o básicamente negativas. Las palabras son: liberalismo, comunismo, socialismo-democrático, capitalismo, socialdemocracia". La respuesta mayoritaria enuncia: ni comunismo, ni capitalismo. El concepto más apreciado por el conjunto de encuestados era la socialdemocracia, con cierto matiz intermedio: "conservadores en lo económico, socialdemócratas en todo lo demás". Una encuesta, decíamos, no dirige la historia; simplemente transfiere un pensamiento. Además, para muchos de los encuestados la opción por algunos de estos modelos no vividos se asemeja a quienes se enamoran de un artista de cine a quien sólo conocen en pantalla. Por ello era necesario discutir y aclarar estas opciones en el presente foro de 1990. Los resultados de esta macroencuesta pueden verse en la siguiente cita bibliográfica ${ }^{27}$.

Enebrando las citas de G. D. H. Cole, de M. Rocard y las preguntas de la macroencuesta europea podemos concluir que la gran alternativa u opción fundamental del mundo de hoy no se reduce a comunismo-capitalismo, plan o mercado, como también lo están pretendiendo ciertos comentarios parcialistas de la reciente encíclica papal Centesimus Annus, como si Juan Pablo II bendijera, con indulgencia plenaria, al sistema capitalista, olvidando los calificativos que, a su tiempo le aplica, de salvaje y primitivo. La realidad hay que verla con todos sus colores ${ }^{28}$.

En el foro de La Sorbona, Michel Rocard, al hablar de la Segunda Intemacional, menciona a Karl Kaustky y otros... En los puntos suspensivos vamos a hacer un breve espacio a Eduard Berstein, compañero de lucha en la etapa de formación clandestina del movimiento socialdemócrata alemán bajo el régimen del canciller de hierro Bismark. La razón de juntar a estos dos precursores de los movimientos socialistas es para recordar que de este mismo tronco común brotan dos ramificaciones divergentes de socialismo, digamos, democráticos. Ambos pensadores y actores de la transición se emparentan al sostener que tanto en la fase de acceso al poder como del ejercicio del poder socialista se debe respetar, histórica y realísticamente, el parlamentarismo pluralista, opuesto al coup d'etat de Lenín, criticado también por 


\section{Rosa Luxemburg.}

Emparentados en este matiz democrático, ambos autores difieren, por cuanto $\mathrm{E}$. Berstein inspira todo un movimiento socialista moderado y realista, donde no corrige, sino que, prácticamente, arrincona a Marx. La teoría del valor-trabajo le parece demasiado etérea y requiere del complemento de las explicaciones marginalistas; el materialismo histórico deja poco espacio al espíritu; la lucha de clases opuestas es demasiado parcial, y conviene sustituir la dialéctica marxista por el sentido común y a Hegel por Kant. Amigo de apegarse al avance de los hechos históricos más que a profecías inciertas, E. Berstein inspira un socialismo moderado, de sabor fabiano, con amplia trayectoria en el continente europeo. Por ello, B. B. Seligman, en su historia del pensamiento económico, comenta: "no obstante, si efectuamos una mirada a la historia del socialismo europeo nos preguntamos si al fin y al cabo no fue Berstein, en lugar de Marx, quien ganó la partida"29.

Esta cita quiere decir que todas las teorias o corrientes científicas están obligadas a confrontarse con la historia, a sabiendas de las resistencias internas que todos tenemos a cambiar nuestras teorías; pero si no lo hacemos nos salimos del carril de la historia. La sovietóloga francesa Marie Lavigne, en el prólogo de su obra sobre las economías socialistas, hace la pregunta que se venian planteando en Europa desde la década de 1970: "las economías socialistas europeas ison socialistas? ¿Lo han sido alguna vez y lograrán serlo algún día?" Para responder a esta pregunta cita la correspondencia entre dos notorios socialistas, $\mathrm{Ch}$. Bettelheim (francés) y P. Sweezy (estadounidense), defensores inicialmente del modelo soviético y fuertes críticos, posteriormente, al igual que E. Mandel, M. Dobb... En su correspondencia, estos autores sugerian que sería necesario aplicar a las formas específicas de formación socialista un trabajo análogo al que Marx efectuó con el modo de producción capitalista. En otras palabras, agrega Marie Lavigne, hace falta otra nuevo Marx que estudiara si la revolución, que él habia anunciado, se habia realizado. Dado que esto no es posible y que, de serlo, el propio Marx se vería en serio aprieto, Marie Lavigne concluye, en el epílogo de su obra, que el verdadero desafío a los socialismos reales les viene lanzado, no desde el capitalismo, sino desde sus principios de solidaridad con sus propios pueblos y con el tercer mundo ${ }^{30}$.

Esta advertencia de Marie Lavigne o esta medida de valor deben tomarla como el gran parámetro democrático todos los sistemas y modelo o regímenes dentro de cada gran sistema. Porque la expresión "solidaridad con sus pueblos y con el tercer mundo" tiene una profunda cargá humana y social, totalmente ausente en el mismo término que nuestra economía de mercado aplica al Estado y su función de "solidaridad", que, de acuerdo a la estructura fiscal, significa simplemente subsidiaridad y suplencia. Ser solidario es algo muy distinto de hacer subsidio o transferencias sociales. Quizás sea ésta una de las grandes reflexiones a que nos ha llevado este largo recorrido de citas históricas. Los grandes sistemas, es decir, los grandes poderes de los sistemas no han mostrado ni solidaridad con sus pueblos, ni solidaridad con el tercer mundo. Sin duda es el mensaje que nos lanza y nos reta el epílogo de perestroika.

\section{Las dificultades políticas de la transición}

Escuchando a los ponentes del foro de La Sorbona se diría que impactó una frase, de tono profético, que dejó caer el primer ministro francés, Michel Rocard, en su ponencia inaugural: "los historiadores nos han enseñado que el siglo XX comenzó en 1914. Sin duda, a partir de ahora, debemos decir que 1989 marcó el comienzo del siglo XXI". También el papa Juan Pablo II dedica el capítulo tercero de su última encíclica social al año 1989 , con lo cual éste adquiere cierto carácter apocaliptico, donde cada quien puede darse el gusto de identificar quién es la bestia, quién el cordero y quiénes son los miles manchados con la sangre del cordero.

Lo cierto es que se adelanta en una década el inicio del tercer milenio. Las conferencias para diezmar los misiles han sustituido a la carrera armamentística, el muro de Berlín ha sido sustituido por la palabra unificación -que en un principio daba miedo-, y sobre todo que, a partir de 1989 el este caminaba hacia el oeste y el oeste veía un gran mercado en el este. A las dos décadas de es- 
tanflación sucederían nuevos vientos de recuperación, primero europea, luego mundial. El nuevo centro de atención, del crédito y de la inversión, desde japoneses hasta norteamericanos, era la nueva Europa (¿hogar común?) de ochocientos millones de habitantes. Se cernía una neblina en el tercer mundo, porque al ir el este hacia el oeste y el oeste hacia el este, una vez más nos tocaría ser el tercer mundo de la deuda externa y del tráfico de drogas.

Por eso, es anecdótico volver a leer lo que uno leyó y uno escribió hace poco más del año. Aunque todo esto se refiera más directamente a aquellos países de allende el Atlántico, sin mayores esfuerzos de traducción lo comprendemos y se nos aplica a nosotros. Decíamos que en la macroencuesta europea unos responden positivamente y otros lo hacen negativamente; pero no hay que olvidar el buen grupo de quienes se abstienen, quizás porque han perdido totalmente su fe en la política, o tal vez, porque no aparece en la encuesta el movimiento que ellos apoyarian. La historia comparada de los partidos políticos ha ensenado que todos prometen mucho y pocos realizan las promesas. En 1989 y ahora, los nombres de liberalismo, comunismo, capitalismo, socialismodemocrático y socialdemocracia, tienen resonancias diferentes, de acuerdo a las experiencias vividas por cada uno según las expectativas y las promesas occidentales; por eso están siendo muy fuertes las decepciones y las resistencias, no sólo en las dos Alemanias unidas.

\subsection{El mosaico europeo}

Hay que corregir la imagen de una Europa unificada por el mercado, el crédito y la inversión. No que la imagen y el ideal sean malos; todo lo contrario; pero todavía estamos a nivel de imagen. Corremos el peligro de este mismo espejismo de mercados unificados, pese a que no son tan necesarios; por ello, analicemos un poco el caso europeo. La nueva Europa es un mosaico compuesto de hombres distintos, de nacionalidades y etnias emergentes, de historias enfrentadas, de aspiraciones a veces semejantes, a veces opuestas. Lo que nos une a ellos es que son hombres en búsqueda de algo nuevo, a partir de algo decepcionante en su realización, pero siempre anhelado como un ideal.

El punto de partida lo podemos resumir con el testimonio de dos acreditados economistas, defensores de la perestroika. A. Grachov, de la Academia de Ciencias de la Unión Soviética, dice lo esencial en pocas palabras: "venimos del país del socialismo real, que ha sido a veces un socialismo irreal, e incluso más que real, ya que albergaba la ambición de estar por encima de la realidad y del realismo. Hay que decir que este socialismo ha fracasado. Lo decimos entre nosotros y lo reconocemos ante ustedes. Pero una cuestión permanece abierta: Leste fracaso es del socialismo en cuanto tal, como ideal, como ambición, como orientación de la evolución de la sociedad y de la humanidad, o se trata de un fracaso particular preciso, desdichado, condicionado por las condiciones especiales de Rusia?". Hace un año, añadíamos el siguiente comentario: "esta intervención de A. Grachov, que resuma sabores de perestroika, explica por qué al interior de la Unión Soviética el más elevado porcentaje de los votos (57 por ciento) se lo llevó el socialismo-democrático. Se sabe lo que hay que quitar, se busca lo que hay que construir".

La pregunta de A. Grachov es globalmente respondida por el congresista N. Petrakov, colaborador de uno de los modelos económicos de la Unión Soviética: "el socialismo es una concepción del mundo, un concepto muy amplio del valor de la personalidad; es una visión de la sociedad que da protección social a la persona, que no sólo protege su libertad, sino que le da unas garantías de satisfacción al margen del aporte del individuo al desarrollo económico del país. Por eso yo pienso que el mercado, como forma de penetración de la democracia socialista en la economía, es nuestra única posibilidad. El mercado no presupone la explotación, como ocurre en el mercado capitalista. Es intercambio democrático lo que hace falta. El mercado y el socialismo son dos conceptos compatibles, y considero que muchas ideas socialistas no pueden realizarse fuera del mercado. Ahora nos enfrentamos al problema de introducir el mercado cuando se está desintegrando el sistema financiero soviético, es decir, cuando no podemos ir del mercado al mercado"31. 
Juntamente con los rusos también los alemanes del este deben hacer su transición obligada. Por ello, G. Gysi, secretario general del PDS, partido para el socialismo democrático, trata, casi simultóneamente, dos temas controversiales en la transición europea. El primero se refiere a las alternativas económicas del este. "Para ellos (los países de Europa oriental) existen dos posibilidades: el socialismo democrático, que implica una sociedad libre y democrática, eficaz económicamente, pero también con unas responsabilidades asumidas en el terreno ecológico y social. Esta idea no tiene que ver con el tipo de socialismo estalinista que se acaba de hundir en el centro y en el este de Europa. El otro camino que aquí se ha defendido como vía liberal o como economía social de mercado, funciona bien y en beneficio de los ciudadanos sólo en muy pocos países. A pesar de la economía de mercado, la mayor parte de la humanidad vive en la más profunda pobreza. La fórmula es que unos pocos países vivan bien a expensas de otros países... Las declaraciones y los programas de los partidos socialistas y socialdemócratas en occidente reconocen que el socialismo democrático, al que aspiran, está lejos de haberse realizado... Una restauración de la economia de mercado, que desembocase finalmente en la dominación de los intereses del capital y de las grandes empresas privadas reemplazaria, a mi entender, una dependencia antigua por otra nueva".

Presentada la encrucijada posible a las economías del este, preferimos que el comentario lo hagan los quince meses de historia que median entre aquella y esta fecha. Para introducir dicho comentario, dejamos que G. Gysi presente el otro tema candente: la unificación alemana. "La unidad no debe asustar a los ciudadanos de la República Democrática Alemana. Habrá que respetar los intereses de los cuatro aliados y los intereses de los pueblos vecinos como los polacos. Un eventual nuevo nacionalismo es inaceptable para encarar la unidad alemana. La unificación alemana debe inscribirse en el proceso de la unidad europea y contribuir a la creación de lo que en palabra del presidente Mitterand será una federación europea. Para finalizar diré que este proceso de unidad está alumbrando una Alemania europea y no una Europa alemana". Diriamos que con estas palabras se inicia la marcha del este hacia el oeste: ¿hacia la economia social de mercado? y ¿cómo les abre sus brazos la economía social de mercado?

\subsection{De la unidad a la insolidaridad: las espe- ranzas perdidas}

¿Qué queda ahora de todo este bello discurso y qué reflexiones podemos hacer para nuestro caso? A modo de respuesta, repasemos algunos titulares de los diarios europeos en el último año.

- Octubre de 1990. "Alemania, nace una gran potencia en Europa. Hacia la unidad a velocidades de vértigo. Día de alegria para todos los alemanes. Un nuevo milagro económico. Satisfacción, reflexión y gratitud. La comunidad europea cree que la unidad alemana da nuevos alientos a su integración...".

- Noviembre de 1990. "Europa hereda de los paises del Este una población envejecida. Helmut Kohl advierte sobre los sacrificios que exige la unidad. La preocupación y el miedo. Por fin unidos, pero ya no tan ricos. Espías hasta en la sopa. La República Democrática Alemana es uno de los rincones más sucios de Europa: el país está hecho polvo...".

- Enero de 1991. “Alemania es otra: un sondeo revela lo que divide y separa a los habitantes del este y el oeste. Los alemanes emigran a Alemania...".

- Marzo de 1991. "Reunificación alemana: del gozo al sacrificio. Bancarrota, mala suerte y colapso: los alemanes de la desaparecida R.D.A. se consideran ciudadanos de segunda (oassis) y extranjeros en su propia patria...".

- Mayo y junio de 1991. "El muro del bienestar: la población de la antigua R.D.A. despierta en la miseria del sueño de la Gran Alemania. No teníamos idea de lo capitalista que era la República Federal Alemana y ellos tampoco sabian lo socialistas que éramos nosotros. Y al año siguiente la miseria: en el aniversario de la unión monetaria 600,000 alemanes del este perderán su empleo...". 
Diriamos que la historia ha comenzado a caminar en dirección contraria al brindis de la unificación. Las transiciones no son nada fáciles y las culpabilidades deben ser compartidas. Repartiendo las cartas, las estadísticas oficiales del este alemán falseaban una realidad caótica. La productividad de la zona este se sitúa en torno al 30 ó 40 por ciento del resto de Alemania. De una población activa de nueve millones, seis millones deberian perder su trabajo para que la industria fuera competitiva. Lo más serio es la falta absoluta de cuadros en los cuales poder confiar para cualquier proyecto. La misma situación ecológica, así como la vivienda, es lamentable, sobre todo en las áreas industrializadas. Por ello, los alemanes del este no saben contra quién revolverse. Antes que nada, dirigen su rabia hacia la era Honecker; pero también se han sucedido las manifestaciones contra el premier H. Kohl, llegando incluso hasta a arrojarle huevos. El clérigo Christian Führer comenta: "cuarenta años de socialismo y diecisiete de dictadura fascista le quitaron toda iniciativa a mis compañeros". Pero lo peor de todo es que los alemanes no se quieren: "los ossis huelen mal", dicen en Berlín occidental; "los ossis no saben manejar, los ossis quieren tocar todo. Pero los ossis tienen que hacer todos los dias dos o tres horas de camino para venir a trabajar en la zona occidental, extranjeros en su propio país. Con la unificación brota la xenofobia. Parafraseando el manifiesto de Marx ("Un fantasma recorre Europa: el comunismo") se puede leer en las calles de Leipzig: "Un fantasma recorre el este: el desempleo". Para los alemanes occidentales la anexión del este les ha supuesto una sobrecarga de impuesto semejante a su contribución a la "tormenta del desierto", y no están contentos con ninguna de las dos tormentas.

El caso alemán sigue siendo objeto de preocupación, porque la unificación se ha trastocado en insolidaridad, no propiamente étnica, sino de ideales y estilos o espíritus de vida. La economía de mercado, aún con el aditivo de social, no está dispuesta a perder su estato o su confort de mercado. La expresión "sentirse extranjeros en su propio país" es una cruel realidad entre las mayorías pobres de nuestro tercer mundo. A las economías del este se les dice $-\mathrm{y}$ ellos lo sienten- que deben dirigirse hacia las economías del oeste, hacia las economias de mercado. Pero, las economias del oeste, las economías de mercado de nuestros oestes, Lestán dispuestas a sacrificar algo de su nivel y de su género de vida para acoger a quienes llegan de todos los "estes" más pobres?

Los participantes polacos, húngaros, checoslovacos... en el foro de La Sorbona sacan a relucir este mismo miedo. "Los comportamientos xenófobos y de miedo respecto del pobre europeo oriental que llama a la puerta del occidente opulento" (G. Geremek, de Solidaridad). Por la semejanza entre ellos y. nosotros, hay que escuchar y hay que entender a estos ciudadanos del este que se mueven entre dos miedos: también el miedo a la misma política. "La política, tal y como se ha venido practicando durante decenios, es un monopolio del poder. El resultado ha sido el rechazo en bloque de la política, del fenómeno partido político. El partido político en nuestros países sigue siendo un fenómeno que se contempla con desconfianza y temor" (B. Geremek). Tal es la fase de transición entre dos miedos: el miedo a la propia política y el miedo al opulento occidente de mercado. ¿No son estos los mismos miedos de nuestros pueblos?

\subsection{Las dificultades políticas internas}

El historiador soviético Yuri Afasaniev, en su publicación Perestroika, única salida, afirma que no puede haber una radical perestroika mientras no se haga una profunda revisión de la historia pasada. Por lo aquí escrito, esta tarea se ha iniciado con todo vigor en medio de fuertes controversias. "A su vez esto nos plantea el tema más general de la altemativa y la variante en la historia de la necesidad de libramos de nuestro materialismo histórico dogmático, el cual presenta el camino recorrido como un proceso rectilíneo regido por leyes apriorísticas determinadas de antemano... De ahí que sea tan importante hoy día el contraste de opiniones, aunque sean contradictorias. Importante la posibilidad de expresar ideas, proyectos, presupuestos y plataformas en publicaciones distintas por su orientación, incluso en las independientes, que no necesariamente sean órga- 


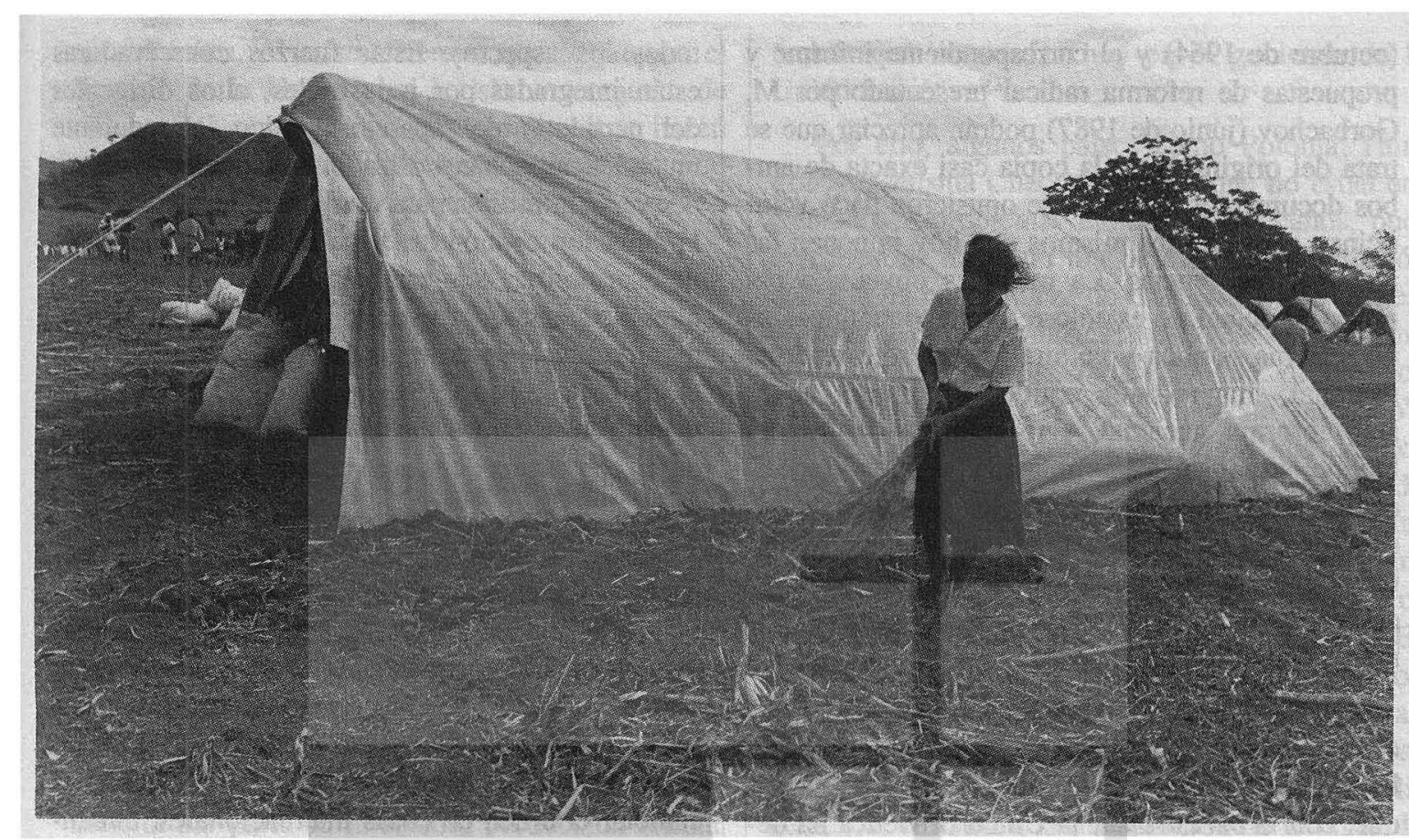

no de alguna entidad".

Detalle bien positivo, Yuri Afasaniev afirma que para realizar una verdadera perestroika hay que pasar por lo que llama la "prueba moral". "Tampoco podemos olvidar las cuestiones morales. El fenómeno del estalinismo implica crímenes y sacrificios colosales; es preciso volver a enjuiciarlo y superarlo, y no sólo con la ayuda de la razón. Es como si entablásemos un diálogo ético con quienes vivian en los años treinta para formarnos una mejor noción de lo que somos nosotros mismos, los que hemos vivido después de ellos sobre la base de nuestra comprensión de su circunstancia. En otras palabras, para llevar a cabo la perestroika debemos pasar por una prueba moral. No podemos excusarnos de la penitencia nacional; todavía la tenemos delante, y no me refiero a un rito singular, sino a la autodepuración moral de cada individuo y de la sociedad en conjunto. Tampoco se puede adquirir una autoestimación moral saludable sin un conocimiento exhaustivo y muy profundo de lo sucedido en nuestra historia pasada y reciente"32.

Sin lugar a dudas, Y. Afasaniev nos ha iluminado para detectar las resistencias políticas y

humanas al cambio, tanto del lado de allá como de acá, donde se ondea el lema de "cambiar para mejorar". Analizar con libertad la historia y someternos a su prueba moral: hacer la historia dialogando con quienes más han sufrido de la historia. Con este preámbulo queda desbrozado el camino para seffalar brevemente las resistencias políticas al cambio. Nos referimos más específicamente a la Unión Soviética y, en su debida proporción, vale para los otros países. En los pasados intentos de hacer perestroika, con Khrutchev (1956...) y con Liberman-Kossiguin (1964...), las reformas de deconcentración geográfica y de descentralización administrativa se limitaron a la esfera meramente económica, es decir, a una remodelación del mecanismo de funcionamiento productivo, redistribuyendo las funciones y alcances del plan central y de los gosplanes regionales, (Khrutchev) o del plan central y de las empresas individuales (Liberman). Pero no se tocó prácticamente la superestructura política, ni la conciencia de quienes detentaban el sumo poder.

Quienes hayan tenido la oportunidad de leer el informe económico y las propuestas de reforma, presentados por A. Kossiguin al pleno del partido 
(octubre de 1964) y el correspondiente informe y propuestas de reforma radical presentado por $\mathbf{M}$. Gorbachov (junio de 1987) podrán apreciar que se trata del original y de la copia casi exacta de ambos documentos. Quienes se opusieron hace veinticinco anos son los mismos que hoy imponen las mayores resistencias. La razón es obvia. La perestroika actual no es sólo reforma económica, sino reforma política y cultural; no es sólo reforma nacional, sino reforma política y cultural; no es sólo reforma nacional, sino reforma dentro del bloque socialista y en relación al mundo occidental. Basta leer el orden de los capítulos de perestroika: el mundo actual, el mundo socialista, el tercer mundo, Europa, el hogar común, las relaciones soviético-norteamericanas. Y los dos primeros capítulos son "nuevas ideas para mi país".

Este orden de los capítulos marca otros tanto escaffos desde donde los adversarios políticos lanzan los dardos de la crítica. La gran crítica es que, con la perestroika, la Unión Soviética ha dejado de ser la gran potencia política del mundo. Se resisten a escuchar la pregunta: ¿sigue siendo la Unión Soviética una gran potencia? Ahora es el citado economista A. Grachov, jefe del departamento de relaciones exteriores del Partido Comunista, quien se ha hecho esa pregunta, y la siguiente: ¿quiénes critican y en qué se centra la crítica? "Las dificultades económicas y sociales que atraviesa la Unión Soviética no sólo no suponen un apoyo a las decisiones de Gorbachov, sino que además han hecho que se ponga en entredicho su política exterior. Hace poco también algunos diputados del Soviet Supremo criticaban con severidad la política exterior de la Unión Soviétiva, diciendo que hemos dejado de ser una gran potencia, que se le hace el juego a Estados Unidos y que ya no tenemos aliados en el Pacto de Varsovia. Para estos partidarios de la anterior política, fundada en reacciones temerosas y en la voluntad de protegerse de toda agresión exterior, el país debería hacer un nuevo sacrificio para mantenerse en paridad con Estados Unidos en todos los aspectos. Estas fuerzas conservadoras están integradas por industriales, altos dirigentes del partido y del aparato político, que durante mucho tiempo han utilizado la pantalla de la superpotencia militar para ocultar la degradación de la situación económica y política. Los defensores de esta política son también numerosos entre los altos dirigentes del ejército, que deploran la pérdida de prestigio de la institución, sobre todo tras el conflicto afgano. Para todos ellos, la URSS ha pagado muy caro el precio de su seguridad, y no debe convertirse en una potencia de tercer orden"33.

Esta cita de A. Grachov explica que M. Gorbachov sea el hombre más admirado fuera y el más criticado dentro de la Unión Soviética. Las mismas medidas anunciadas en perestroika para lograr una distensión internacional son criticadas internamente como un signo de debilidad política. "Los soviéticos hemos tomado la iniciativa de cambiar el orden de cosas internacionales, tomando decisiones espectaculares: la liberalización en la Europa del este, medidas unilaterales de desarme, retirada de ciertas regiones del tercer mundo. Puede analizarse esta nueva política en términos de debilidad política y de retroceso para la URSS. Pero, en realidad, hay que ver en ellas la capacidad de correr el riesgo de imponer nuevas relaciones internacionales, cosa que no sería verdad sin una cierta dosis de audacia política en relación a las críticas intemas que esta actitud no deja de suscitar"'34.

A estos críticos se unirán otros nuevos grupos en razón de dos hitos que debían enfrentar los dirigentes del gobiemo: el tema espinoso de las nacionalidades-repúblicas, y en segundo lugar, qué modelo de reestructuración económica implantar. Respecto al problema de la nacionalidades y del Tratado de la Unión, V. Korotich, director de la revista Ogonyok, dirá que "actualmente Gorbachov está tratando de ser Salvador Allende y Augusto Pinochet a un mismo tiempo, lo cual resulta difícil" y supone un comportamiento es-

\section{Los grandes sistemas, es decir, los grandes poderes de los sistemas no han mostrado ni solidaridad con sus pueblos, mi solidaridad con el tercer mundo.}


quizofrénico. Al mismo tiempo que se prepara el Tratado de la Unión y se legisla un conjunto de autonomías republicanas, se permite o se hacen oídos sordos a la ruda intervención del ejército en Lituania. Lo que ya se no se hace fuera, se hace dentro de la Unión Soviética.

Las críticas y las presiones vendrán simultáneamente de quienes luchan por una mayor independencia (las repúblicas bálticas, Ucrania, Rusia...) y del otro lado, los conservadores integrados en el equipo soyuz (unión) que rechaza todas las transformaciones que dan protagonismo a las repúblicas y a nuevos sectores sociales. Totalitaristas del antiguo régimen y buena parte de los mandos militares, que se resisten a ver disminuidos sus poderes, sus privilegios y también el presupuesto militar. Como la reforma política reclama un proceso de elecciones populares para integrar el Congreso de Diputados y los soviets de las repúblicas, y como la reforma económica requiere transformar parte de la costosa producción militar en producción civil, los antiguos privilegiados del poder se resisten a la prueba moral de la historia.

Como dice acertadamente Jeffrey Sachs, asesor de varios países del este, "el debate sobre política económica en la URSS es fundamentalmente sobre el reparto del poder político, y no tanto sobre sus diferentes alternativas o aspectos técnicos"... El economista Guillermo de la Dehesa, en su artículo dedicado a "La curva de Gorbachov", agrega su propio comentario al del citado asesor del este. "El problema fundamental de Gorbachov es que la reforma económica necesaria en la Unión Soviética supone, de un lado, la transferencia de buena parte del poder político, y por tanto, del control de la riqueza, a los gobiernos elegidos democráticamente en las repúblicas; $y$, del otro lado, la transformación de buena parte de la propiedad estatal a los ciudadanos; y ambos supuestos amenazan con derrumbar la base del poder del partido comunista, detentado centralizada y opresoramente, durante muchas décadas... Lo malo es que la experiencia histórica nos viene demostrando que las difíciles y traumáticas transiciones políticas y económicas sólo se pueden llevar adelante por gobiemos elegidos democráticamente y con amplio apoyo popular, supuestos ambos que no se dan hoy en el gobierno de la Unión Soviética"35.

Por ello, algunos paises como Polonia, Hungria y la misma Checoslovaquia, que no están enfrentados a problemas étnicos republicanos, pueden avanzar hacia un mayor nivel de producción sobre la llamada "curva de Gorbachov". De acuerdo a algunos economistas españoles, el problema de la Unión Soviética radica en que, desde hace tiempo, se encuentra "sin plan y sin mercado". Gorbachov habia creído al principio que era posible una tercera vía que él mismo había llamado socialismo de mercado, que combina las relaciones de la economía de mercado con el mantenimiento de la propiedad de los medios de producción e intercambio en manos del Estado. Es normal que los conservadores, que administraron privadamente la propiedad estatal, se opongan teórica y prácticamente a los decretos de privatización en el agro y en la industria pesada y ligera, y se resistan a la introducción de la bolsa de valores y a la distribución de acciones en compañías nacionales y extranjeras. El tema de la propiedad social y de la propiedad privada toca un punto neurálgico de la teoria y praxis soviética. Pero, en el fondo, ya lo hemos repetido, es el problema del reparto del poder político lo que está en juego.

Explicando la tesis con un ejemplo, un periodista del diario El País sostuvo una entrevista con Yegor Ligachov, símbolo de la ortodoxia conservadora. En forma de diálogo, pregunta y respuesta, este exilado del Politburó y del Kremlin, patentiza sus recelos a las nuevas reformas. "A la política de la perestroika le falta continuidad. La propiedad privada, la conversión de la tierra en objeto de compra-venta, contradicen la continuidad de nuestra política. La perestroika en nuestra sociedad debe realizarse sin tocar la palabra socialismo y basándose en la propiedad social de los medios de producción. Hoy se promueve la idea de mercado y el principio de planificación ha sido excluido o arrinconado. No se trata del plan que teníamos antes, sino de un pronóstico que diera las líneas maestras de la economía. Estoy por el mercado socialista, y éste presupone la regulación estatal también de la 
formación de precios. Yo no entiendo la consigna de mercado libre, que aparte del caos político y social, sólo traerá desgracia y subida de precios a nuestra gente".

Esta primera respuesta es un indicador de las dificultades en que se debate el actual régimen que debe escoger entre la continuidad y el cambio radical. La postura representada por Y. Ligachov se enmarca en el artículo 10, capítulo II de la Constitución de la Unión Soviética (1977). "El fundamento del sistema económico de la URSS esta constituido por la propiedad socialista de los medios de producción bajo forma de propiedad del Estado (de todo el pueblo) y de la propiedad kolkhoziana cooperativa... Nadie tiene el derecho de utilizar la propiedad socialista para fines lucrativos personales u otros fines particulares"36.

Los siguientes artículos, del 11 al 16, concretan el ordenamiento jurídico de la controvertida propiedad social y del patrimonio nacional, tradicionalmente administrado por y predestinado a muy pocas manos. Si bien Y. Ligachov contrapone propiedad social a propiedad privada, el verdadero problema se centra en elegir y combinar la administración estatal de algunos sectores estratégicos (propio de toda economía) y la administración privada empresarial de la producción civil bajo diversas formas de propiedad privada, cooperativa, mixta o por el sistema de accionariado, como veremos más adelante. El punto débil del artículo 10 es que la propiedad del Estado nunca fue propiedad de todo el pueblo.

Y. Ligachov no pretende regresar al antiguo sistema de planificación administrativo de ordeno y mando, apoyando el uso de los planes pronóstico, aspecto valioso y necesario; sin embargo, pretende dar una desafortunada marcha atrás al sostener que el Estado debe ser el regulador de los precios. Esto es, en el caso de la Unión Soviética, olvidar y ocultar los costosos errores cometidos en el pasado, cuya reforma ya está sobrepasando los seis años proyectados para dar el verdadero valor a los precios al por mayor y al por menor. Es cierto que la Unión Soviética está enfrentando un serio problema de inflación real y monetaria, dado que no juegan ni el plan ni el mercado. Sin ser, en forma alguna, defensores del libre mercado, la inflación soviética no se ha generado en virtud del mercado que no existe, o que sólo existe como mercado negro. La explicación hay que buscarla en la escasa oferta de productos civiles, en la deficiente comercialización y en el exceso de liquidez, acumulado en las cajas de ahorro, dado que no encuentra la correspondiente oferta. Estas críticas evidencian las resistencias teóricas y políticas a las reformas, y explican por qué la "curva de Gorbachov" se halla en el punto más bajo de producción.

Otro ítem del diálogo fue: "¿qué haráa usted, en lugar de Gorbachov, para mantener la integridad del Estado?". Del 25 de noviembre de 1990, cuando tuvo lugar esta entrevista, hasta la fecha de hoy, se le han abierto muchas goteras al Partido Comunista, dentro y fuera de la Unión Soviética. Con todo, la respuesta de Y. Ligachov encaja con la posición del movimiento soyuz. "¿Qué fuerzas pueden conservar la unidad del Es. tado? En primer lugar, el Partido Comunista. Con todas las dificultades que hoy vive, el partido tiene la red más extensa de estructuras. Ninguna organización estatal tiene una estructura tan extensa como el PCUS. El partido puede garantizar la construcción de un Estado sobre una base federativa". Precisamente, luego de la mayoritaria elección popular de B. Yeltsin, como presidente de Rusia, uno de sus primeros decretos ha sido evacuar al Partido Comunista de todo el andamiaje republicano en donde estaba incrustado. Tenemos aquí otra línea de resistencias políticas, que muestra por qué $Y$. Ligachov y los suyos se oponen gradualmente a M. Gorbachov, a B. Yeltsin y a A. Yakolev (el gurú de Gorbachov); a éste último por el apoyo que ha dado a los medios de cultura y comunicación que, al decir de Ligachov, son destructivos, falsos y hostiles. He ahí la oposición a la glasnot (verdad).

Aunque la entrevista toca una amplia gama de temas, vale la pena detenerse en otro punto controversial, donde el ala conservadora sigue anclada en una lectura parcial de la historia socialista soviética. "¿No siente usted responsabilidad por la destrucción del socialismo en la Europa del 
este y la desintegración del Pacto de Varsovia?... Considero que el precio pagado por las cosas positivas que han ocurrido en el mundo ha sido muy alto y que los procesos que hoy ocurren en Europa han costado mucho al socialismo; se han dado a costa de la pérdida de un grupo de estados socialistas. Hemos pasado de un régimen socialista común a la construcción de lo que se llama la 'casa común europea'. No puedo aceptar ni estar de acuerdo en que el camino a la casa común europea se haya tendido sobre las ruinas del socialismo en un conjunto de países del este. Creo que es muy ingenuo explicar lo ocurrido en Europa del este como el resultado de un conjunto de errores de los dirigentes de estos países, entre ellos no haber emprendido una amplia democratización de la sociedad y del partido. Lo ocurrido no es sólo el resultado de un proceso interno, sino de una influencia exterior, sobre todo de los servicios secretos occidentales"..." .

No es fácil dar un calificativo a esta retórica respuesta, que pretende ignorar y hacer ignorar el comportamiento estalinista-brezneviano de los Honecker, Novotny, Ceaucescu, Alia..., y recurrir, como un deus ex machina, a los servicios secretos occidentales. No es que seamos muy afectos a ellos, pero tampoco hay que meterlos en la sopa; y más vale ver la viga en el ojo propio... Como bien ha dicho Y. Afasaniev, esto es negarse a pasar por la prueba moral de la historia.

Con este combinado de entrevistas y de testimonios hemos podido delinear algunos cauces de las resistencias políticas internas, que se agudizaria todavía más con todo el proceso de la reestructuración económica. Aquí la mala praxis tratará de defenderse con una deficiente teoría.

\section{La reforma radical de la administración de la economía}

Este es el título de la segunda parte del informe de $M$. Gorbachov al pleno del Partido Comunista, en junio de 1987. Todas y cada una de las palabras son claves. Se busca una reforma radical, es decir, que va a la raíz misma de la crisis o del derrumbe, como se quiera calificar el presente deterioro económico. Pero la raíz del pro- blema no está en contraponer mercado a plan y en dosificar cuantitativamente las esferas de acción de cada uno. El problema está en la transnaturalización del plan. Por todo lo aquí dicho y leído, la raíz del problema es ideológica y política: el plan, en vez de ser un instrumento de política económica, se convirtió en el eje determinante de la economía política, de las relaciones de producción, desnaturalizando el concepto de propiedad social y enajenando a las empresas y a la clase laboral de toda iniciativa y creatividad. Cuando el plan se apropió, por añadidura, de las funciones del mercado, surgió la pregunta ¿quién planifica al planificador?

Pareceria entonces que la raiz y la causal del deterioro económico están en la planificación. Tampoco esto es cierto. Mal hacen aquellos comentaristas occidentales que ponen el origen del mal en la planificación para deducir festinadamente que la solución está en el libre mercado. Esto, además de un error, sería una autoacusación. El punto de partida de toda administración económica de la empresa es la planificación, la organización, la ejecución, el control-evaluación y de nuevo la planificación. Si es dado jugar con las palabras, podemos decir que nada hay menos libre que la libre empresa, donde todo está predeterminado e integrado a un fin común. En consecuencia, la planificación, en cuanto planificación, no es un error económico, sino un comportamiento humano para orientar la libertad responsable, a nivel empresarial y nacional. El error teóricopolítico estuvo en convertir el plan en el instrumento de concentración e imperialización de toda la economía.

Por otra parte, conviene recordar la historia y la deuda que las economías capitalistas han contraído con las economías socialistas, desde la década de los años 1930. Para aquellas fechas, el simple juego del mercado había zarandeado a las grandes economías arriba y abajo en trece ciclos que terminaban en trece crisis de desconcierto y desempleo. Entonces, surgió la preocupación por el crecimiento armónico y ahí nació la necesidad de orientarse con planes de desarrollo. En occidente hablamos de tres sectores económicos: primario, secundario y terciario, que además de 
indicar una secuencia estructurada traducen el paso de tres civilizaciones, la agraria, la industrial y la vuelta al hombre con los servicios. En las economías del este utilizaban una imagen muy apropiada para orientar al plan y a los planificadores: el proceso económico era descrito como una cadena integrada por "eslabones", engarzados secuencialmente los unos en los otros.

En la década de 1920, Wassily Leontief (iniciador de las matrices intersectoriales en Harvard, premio Nobel de economía) trabajó en la elaboración de esos eslabones y en la preparación de sus respectivos balances que cuantificaban los componentes de una fila y una columna de sus posteriores matrices insumo-producto. $\mathrm{Si}$, a decir del mismo autor, él se inspiró en "el cuadro económico de Quesnay", sin duda adquirió experiencia práctica en la preparación de estos balances, punto de partida de la planificación. Directa e indirectamente, las economías capitalistas se inspiraron en ese modelo de eslabones y balances para perfeccionar las matrices intersectoriales, que por décadas han servido como la carta de navegación de los planes de desarrollo europeos y de los nuestros. Alguna explicación hay que buscarle al esfuerzo que nuestro Banco Central de Reserva viene haciendo (y no es el único) para actualizar nuestra matriz insumo-producto 1978 , hasta nuestros días. Problema distinto es que nuestros "planificadores" se olviden de que existe esta carta de navegación y prefieran otro timonel.

Y. Ligachov, en la entrevista mencionada, ha hecho una distinción muy importante, sobre todo saliendo de su boca. El no pretende regresar al antiguo sistema de planificación, que prefijaba a través de hasta 500 índices todos los coeficientes técnicos (detalles cuantitativos) de todos los imputs y outputs; pero defiende los "planes-pronósticos". Sin detenernos en tecnicismos, los planespronósticos señalan los objetivos que se desean alcanzar en veinte o diez años vista, y sirven para retrotraer, en forma de planes quinquenales y anuales, las correspondientes metas sectoriales de producción. A estas metas sectoriales se les llamarán "cifras de control", tal como las podemos encontrar en la página 30 de nuestro "Plan de desarrollo", como "indicadores económicos seleccio- nados, 1989-1994". La economia de mercado no desdeña, ni puede desdeñar, la orientación del plan.

A veces oímos decir que nuestra economía es o está truncada y dependiente, como tela de araña rasgada. Precisamente, eso es lo que buscan corregir los planes-pronóstico, con todas las relaciones de interdependencia que nos muestran, para traducirlos en planes de acción quinquenales y anuales. No seamos tan antiplanificadores, cuando en nuestras economías utilizamos estos instrumentos, o por lo menos, ahí están aunque no se utilicen; pero la culpa no es del instrumento. Cuando en las economías del este se habla de "mercado orientado por el plan" (leeremos luego a A. Aganbegian) se refieren a esto: que plan y mercado pertenecen a la esencia de una economía socialista, y de cualquier otra economía. El arte económico está, en cada lugar y momento, en conjugar las funciones de ambos mecanismos de funcionamiento, de manera que se logre una retroalimentación de control y orientación del plan y del mercado.

\subsection{El importantísimo eslabón del proceso de renovación}

Esta es la segunda parte del título: "la reforma radical". Nadie discute que hay que renovar las economías del este. Renovar es hacer algo nuevo, modemizado, sustituyendo la costosa inversión extensiva por una inversión intensiva, tecnificada y optimizadora de recursos. Aquí nos topamos con un misterio económico y político para los mismos soviéticos y sovietólogos. En nuestros países en desarrollo, hablamos de economía formal y economía informal; la primera se apropia de los mejores recursos humanos, físicos y financieros, mientras que la segunda vive de los residuos. En las economías del este, sobremanera en el caso de la Unión Soviética, hay que distinguir claramente dos economías: los sectores bélicos y espaciales, y con ellos, más intimamente relacionados, que han absorbido tradicionalmente los mejores técnicos bien remunerados, las más avanzadas técnicas científicas, junto con las secretas e indiscutibles partidas del presupuesto estatal. La agricultura y la industria civil se han visto relegadas al "prin- 


\section{El error teórico-político estuvo en convertir el plan en el instrumento de concentración e imperialización de toda la economía.}

cipio del residuo". Verdadera dicotomia económica.

Lo dice sin ambages $M$. Gorbachov, "el impulso a la producción bruta, en particular en la industria pesada, se convirtió en un objetivo 'prioridad uno', casi un fin en sí mismo. Lo mismo sucedió con la capitalización (inversión), donde una considerable parte de la riqueza nacional se convirtió en capital ocioso... Se convirtió en algo típico de nuestros especialistas en economía, el pensar, no en cómo elevar el activo nacional, sino en cómo colocar más material, más mano de obra y más horas de trabajo para venderla a precios altos. Por lo tanto, a pesar de esa producción bruta, había escasez de productos... Esto llevó a la aparición del asi llamado 'principio residual', de acuerdo al cual, los programas sociales y culturales recibian lo que restaba del presupuesto, después de las asignaciones para la producción. $\mathrm{Pa}$ recia haber un 'oído sordo' ante los problemas sociales... Con sorprendente exactitud, nuestros cohetes pueden encontrar al cometa Halley y volar a Venus, pero codo a codo de esos triunfos científicos y tecnológicos, hay una evidente falta de eficiencia en el uso de los logros científicos para las necesidades económicas, y muchos de los artefactos domésticos soviéticos son de mala calidad"38. $^{\text {"38 }}$

Parte del misterio soviético es que en esas economías también encontramos una economía formal y otra informal, deficiente en calidad y cantidad. Prosiguiendo en la develación del misterio, qué interpretación dar a la propiedad social del artículo 10 de la Constitución, entendida como propiedad del Estado, iy de todo el pueblo? La cadena de los "eslabones preferenciales" se rompió en dos: la atendida y la desatendida. Con ello, avanzamos a otro capítulo del misterio soviético. Andrei Grachov nos decía que los grupos más adversos a las actuales reformas están integrados por industriales, altos dirigentes del partido y del aparato político y por numerosos altos oficiales del ejército. No hace falta decir que no son mo- tivos socialmente patrióticos los que mueven a estos grupos, sino el temor a perder los privilegios económicos y el poder político. La burocracia política privilegia, a través del plan, los sectores bélicos y espaciales para mantenerse en el poder con el apoyo de la alta casta industrial y militar. Parece que esta misma táctica también se utiliza en otros países... Bajo la superficie del plan y del mercado hay algo más feo y más antisocial.

Queda todavía otra esquina del misterio soviético, y por ello citamos esas pocas líneas de Perestroika, invitando al lector a revisar esas páginas. Andre Gunder Frank señala, al igual que otros economistas, que los países socialistas, en general, ocupan un puesto intermedio en los intercambios mundiales. "Los países socialistas importan tecnología del occidente, y para pagarla, exportan dos terceras partes de combustible y materias primas y una tercera parte de manufactura. Pero las exportaciones socialistas al tercer mundo, a su vez, consisten en dos terceras partes de productos manufacturados de bajo nivel tecnológico y sus importaciones consisten en dos terceras partes de materias primas. Esto es, las economías socialistas ocupan un lugar intermedio en la división internacional del trabajo: la relación este-socialista y tercer mundo es similar a la relación occidentecapitalista y este-socialista" ${ }^{\text {39. }}$

Este párrafo, siendo globalmente cierto, nos lleva al misterio de la transferencia tecnológica: A todos nos han entretenido las películas del espionaje tecnológico; para que tal espionaje no tuviera éxito se fundó, en París, en 1949, el CO. COM, Comité de Coordinación, que agrupa a los países de la OTAN y controla la exportación de productos catalogados como estratégicos hacia las economías del este. Se diría entonces que las economías del este requerían necesariamente de la tecnología occidental, y que, por lo tanto, era el occidente quien levantaba un muro defensivo contra el espionaje o la compra-venta de tecnología. Esto es cierto, pero parcialmente cierto, es decir, parcialmente misterioso para los mismos sovie- 
tólogos.

De sobra sabemos que la tecnología soviética bélica y espacial puede emparangonarse con su similar norteamericana y competir por el itinerario del cometa Halley o del planeta Venus. La reciente cumbre de ambos presidentes, en agosto, nos ha podido dar cierta calma, porque ambas superpotencias tienen todavía capacidad para destruirse y destruir dos veces a toda la humanidad. La calma viene del hecho de ser tan autodestructivas que no las usarán; más peligrosas son las "tormentas del desierto", que destruyen a terceros solamente. La pregunta que se hacen muchos sovietólogos es por qué esa avanzada tecnología de los "eslabones privilegiados", que por décadas ha sido secreto intransferible, en nada o en poco ha servido para tecnificar al resto de la producción civil, confirmando la estructura de exportacionesimportaciones mencionada. El retraso tecnológico y el derroche de los abundantes recursos físicos y humanos tiene una explicación interna e intrínseca al modelo centralmente planificado por la burocracia política. Dijimos anteriormente que el plan dejó de ser un buen instrumento de política económica para transnaturalizarlo en el instrumento determinante de la economía política. Este ataque aparece en Perestroika y en los grandes lineamientos de las reformas económicas, extractados del informe de A. Aganbegian.

Por esta razón, varios economistas occidentales, marxistas o filomarxistas, que inicialmente defendieron el modelo centralmente planificado desde sus funciones económicas, se volverán serios críticos del mismo cuando se transforme en instrumento del pleno control político. En la década de los sesenta, se hace la pregunta, ¿las economías socialistas, son socialistas?; ¿lo han sido alguna vez y llegarán a serlo algún día? Uno de los acontecimientos más reprobados fue la invasión a Checoslovaquia y la destrucción de la primavera de Praga en 1968, que buscaba instituir un socialismo de rostro humano. La inmensa mayoría de partidos socialistas y comunistas europeos critican la invasión. El diario Pravda la justifica diciendo que Checoslovaquia se está pasando al capitalismo. En esta ocasión, se enlaza una caliente correspondencia entre dos notorios socialistas que, sumando carta a carta, nace un libro. Por brevedad, seleccionamos unos pocos párrafos que hacen al caso.

Paul Sweezy escribe. "No, la invasión soviética a Checoslovaquia no trataba de controlar el viraje iniciado hacia el capitalismo. Lo que temían los dirigentes de la Unión Soviética -y tenían todas las razones para temer- era la doble amenaza que se cernía sobre sus intereses personales y sobre los intereses del estrato gobemante nacional que ellos representan. $\mathrm{La}$ amenaza a sus intereses personales era clara... Pero había otra razón que afectaba de manera especial a los dirigentes soviéticos, dada la posición dominante que tenían en el conjunto del bloque. Al aumentar la importancia del sistema de mercado en el área, crece también la atracción ejercida por las economías de mercado de occidente, más poderosas en este terreno. Una vez que los conceptos de beneficio y de eficiencia han sido promovidos en los niveles de empresa y fábrica al status de valores supremos, es inevitable que la administración de las empresas busque una relación más estrecha con quienes dominan y saben poner mejor en práctica estos valores. En esta situación, forzosamente ha de aumentar la demanda de comercio, de tecnología, de financiamiento $\mathrm{y}$, finalmente, de inversiones de los países capitalistas desarrollados... Sin duda, para la capa gobernante en la Unión Soviética esto representa un grave peligro. El bloque ha sido estructurado económica, política y militarmente para servir a aquel grupo y a sus intereses nacionales".

El segundo correspondal es Charles Bettelheim, que tiene varias obras sobre el socialismo y más específicamente sobre la vía china al socialismo. Charles Bettelheim nos lleva al meollo de la naturaleza del plan, que es el punto aquí importante. "Durante mucho tiempo no se ha tenido en cuenta que puede existir una planificación y un plan burgueses, lo mismo que pueden existir una planificación y un plan proletario o socialista. Identificando plan con socialismo y mercado con capitalismo (lo que es cierto como tendencia) se ayuda a la burguesía, especialmente a la burguesía soviética, a ejercer su dominación al abrigo de un plan, en cuyo nombre retira todo derecho de ex- 
presión a las clases explotadas y con cuya ayuda puede agravar aún más la explotación de las masas... Cuando el plan no es éste 'concentrado' (de la voluntad y aspiraciones de las masas) es un plan burgués, y no un plan socialista; no es 10 contrario del mercado, sino su complemento o su sustituto provisional. Esto que acabamos de decir ha sido en la práctica ignorado durante mucho tiempo, incluso por mí mismo" 40 .

Una autoridad reconocida en el estudio de las economías socialistas, y también del capitalismo, es M. Dobb, que junto con los dos autores antes citados ha ido evolucionando de la defensa inicial a la crítica posterior del modelo centralmente planificado soviético. En su libro, El nuevo socialismo, dedica el último capítulo al tema de la descentralización y democratización. Escrito luego de la invasión a Checoslovaquia, preanuncia los cambios que debían realizarse en estos regímenes. Sólo un párrafo final. "Es imposible prever por el momento con alguna seguridad cuál será la dirección e intensidad del futuro cambio. En algunos aspectos principales podría aventurarse que la planificación y la administración socialista a comienzos de los affos setenta se encuentra en una encrucijada... En otras palabras, la cuestiớn de qué dirección emprenderá es incluso una cuestión más política que económica, como hemos intentado demostrar, relacionado como está con el grado de democracia a conseguir y la cuantía de participación de los trabajadores individuales, de una parte, y de los consumidores individuales, de la otra, en decidir el modo en que y los fines hacia los cuales el sistema de producción se encamina. Aun con evidentes señales de congelamiento de estructuras burocráticas desde la marcha atrás de la reforma en Checoslovaquia en 1968-1969, es apenas probable que la nueva era tecnológica y los niveles de vida más altos puedan tener cabida dentro del viejo molde administrativo heredado de los días de Estalin. Los problemas económicos adquieren a veces una lógica ineludible por sí misma. Puede que presenciemos el rápido cambio de alineaciones e hitos en el mundo socialista durante la

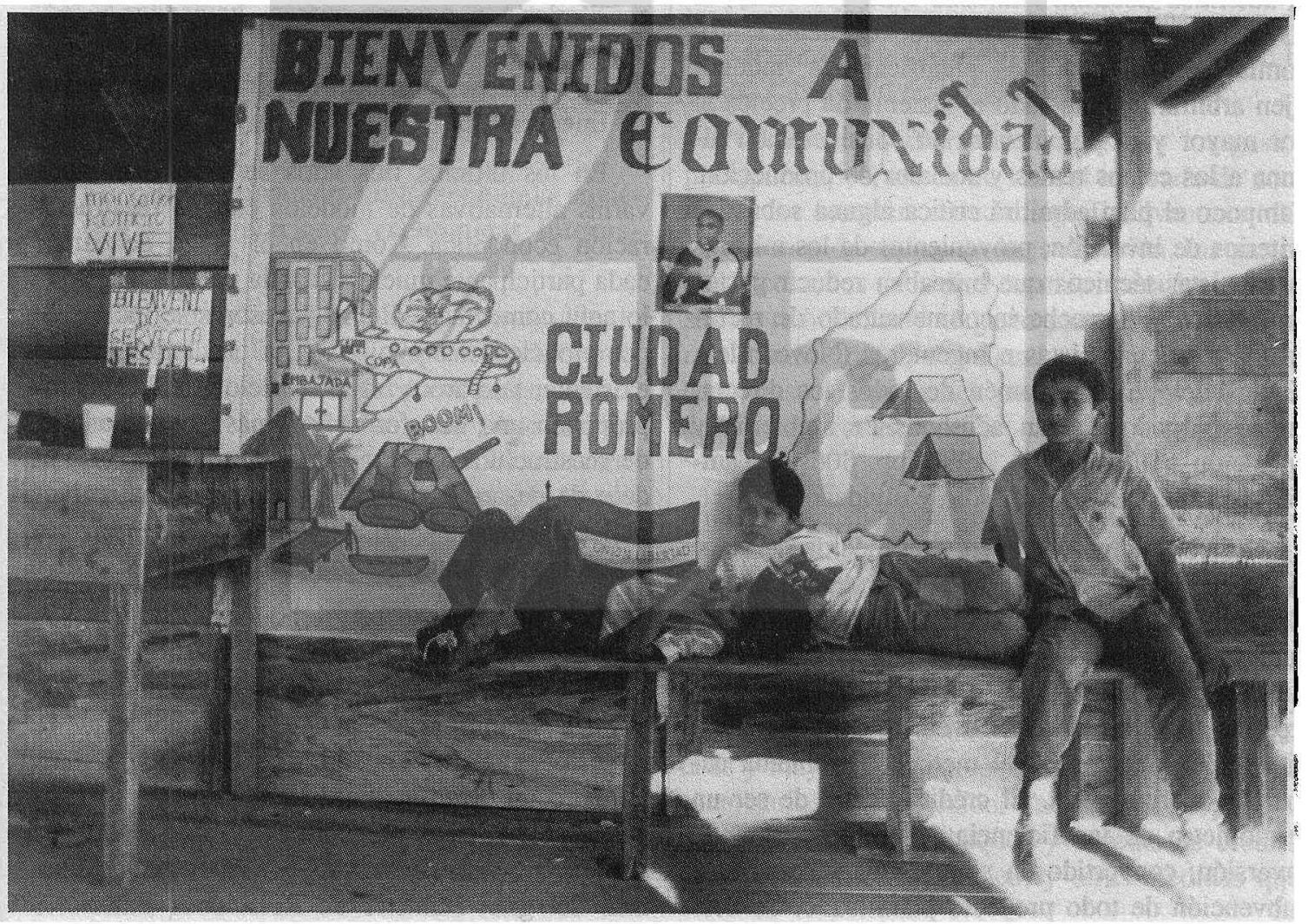


década que nos aguarda"41.

Como lo dan a entender este grupo de notorios socialistas, la raíz del mal está en la deformación lel plan y en su doble consecuencia: un plan aconómico -y por ello defendido por estos economistas - se convierte en mecanismo de dominación y enajenación política y económica. El plan, utilizado para privilegiar determinados sectores bélicos y espaciales..., dadas las circunstancias de confrontación con occidente, partió la economía en dos, relegando al principio residual la producción y los servicios civiles, sin mayor transferencia tecnológica, que hoy de nuevo ha de buscarse en los proyectos e inversiones occidentales. Esta ha sido una gran contradicción interna del modelo centralmente politizado.

A modo de corolario de lo hasta aquí dicho y a modo de preámbulo a los modelos alternativos en vías de introducción, este modo de planificación marchitó en su camino las mejores propuestas de los economistas e ingenieros, invocando siempre la auténtica doctrina marxista. Para comenzar, el sistema de precios no gozará de la menor autonomía; será el plan, los planificadores, quienes fijen arbitrariamente todo el sistema de precios al por mayor y al por menor, sin consideración alguna a los costos reales y sociales de producción. Tampoco el plan admitirá crítica alguna sobre los criterios de inversión, provenientes de los mismos proyectistas técnicos que buscaban reducir gastos financieros y derroche inconmensurado de recursos. Estos economistas e ingenieros (Novozhilov, Kantorivich, Luria..., amén de todos los directamente purgados) serán acusados de ambición y oposición política (ECA, 1990, pp. 306ss). También E. Liberman muere "sólo y olvidado".

Tampcco la moneda será una medida de valor ni de libre intercambio, quedando reducida a simple numerario de una contabilidad ex-post de las cantidades ordenadas (control por el rublo). La función que cumplirá es de reserva de valor, ahorro, en las cajas de ahorro cuando no se hallan bienes de consumo en el mercado: problema actual de sobreliquidez. El crédito dejará de ser un termómetro de la eficiencia empresarial y de la inversión, convertido en simple financiamiento o subvención de todo proyecto planificado. Se des- conoce el término prosentirevanie (tasa de interés), y el capital se distribuye como bien libre. Con ello, la inflación real crece (la escasez) y todo el arte de los directivos ministeriales y empresariales es acaparar, por medios ilícitos, la mayor cantidad de recursos físicos, financieros y laborales, que escasean progresivamente. La inversión extensiva, ajena a los avances tecnológicos, presiona la mayor escasez y derroche de recursos (Perestroika, pp. 18-22) sin que se resienta el sistema de precios, ni el flujo de los créditos. Como le ha dicho Ota Sik, el plan politizado se resiste a toda orientación que venga del mercado, del sistema de precios, de la competencia empresarial, calificándolos de mecanismos capitalistas.

Al existir esas dos economías, la formal privilegiada y la informal sometida al principio del residuo, creció también la tercera economía, la economía subterránea (la economía al claro de luna) para atender los servicios domésticos que las otras no atendían. Los modelos altemativos se están viendo trabados también por la inexperiencia económica.

4. La reestructuración económica: los nuevos lineamientos

En los últimos tres años se están barajando varias alternativas de modelos para la reestructuración económica. Como en el juego de cartas, cada participante quiere ganar la partida. Por todo lo aquí comentado, algunos asesores se inclinarán por modelos más evolutivos, a partir del sistema existente; tal parece ser el modelo Abalkin. Otros proponen una transformación más revolucionaria, de reestructuración, "que exige modificar el modelo de desarrollo y realizar cambios cualitativos radicales en el sistema económico mismo". En esta línea va el modelo Sathalin Esmeliov.

Los modelos y las remodelaciones no son simplemente reformulaciones de medidas económicas, sino que inciden en la remodelación política. Dentro de los vaivenes y tirones a que se ha visto sometido el mismo M. Gorbachov, a ratos más proconservadores, últimamente más prorradicales, se ha visto parcialmente abandonado por antiguos asesores y cercanos adláteres, que además del gran Ministro de Relaciones Exteriores 
Sevarnazhe integra un buen grupo de economistas, adscritos al movimiento Unión Democrática. En los últimos meses han ganado renombre las propuestas del joven economista G. Yablinsky (o Yaulinsky), colaborador del "programa de los 500 dias". Joven economista de 37 años, descubierto y patrocinado por $\mathrm{W}$. Leontief, fue invitado por Washington para participar en la reunión cumbre de los siete, el pasado mes de julio. Es normal que tanto M. Gorbachov como B. Yeltsin se lo quieran ganar a su causa más directa; pero G. Yablinsky se mantiene fiel a su propio modelo, confeccionado con la ayuda de expertos de la Universidad de Harvard.

Dentro de los documentos aquí disponibles está el amplio y detallado diagnóstico y sumario de recomendaciones, preparado por técnicos de las principales instituciones financieras internacionales, citado anteriormente. Sin entrar en los detalles y quedándonos al nivel de los grandes lineamientos, que pueden interesar al lector, hacemos una transcripción resumida del informe preparado por Abel Aganbegian, asesor cercano a Gorbachov, intercalando algunos breves párrafos del informe de Gorbachov al pleno del Partido Comunista, en junio de 1987.

\subsection{La reestructuración de la economía sovié- tica y las relaciones económicas interna- cionales}

"El sistema administrativo de manejo de la economía de la URSS, con su prolongado dominio, ha tenido profundas consecuencias en el país. Las inversiones industriales y el gasto militar predominaban en la estructura del PNB, mientras que el financiamiento del bienestar del pueblo y el desarrollo social dependian del llamado principio del residuo. La perestroika heredó un presupuesto público deficitario, un gran excedente de dinero en manos de la población, no respaldado por suficientes bienes de consumo, escasez de múltiples productos en el mercado, amplia insatisfacción por las condiciones de la vivienda y una situación desastrosa en el campo de los servicios de salud, la educación y las pensiones.

"Durante la perestroika se ha preparado una estrategia fundamentalmente nueva de desarrollo socioeconómico; concentrar los esfuerzos en elevar el nivel de vida del pueblo, insistir en lo cualitativo (mayor eficiencia y mejor calidad) y no sólo en lo cuantitativo, acelerando el progreso científico-técnico; reformar de manera radical la gestión económica, sustituir el sistema administrativo gerencial por los mecanismos de mercado, y estimular, por medio de la apertura, la participación de la economía soviética en los mercados mundiales...

"Sin embargo, todos estos cambios positivos van con lentitud. Más aún, están acompañados de tendencias negativas que dificultan la vida. El déficit presupuestario aumentó significativamente, llegando a 120,000 millones de rublos anuales (más del 13 por ciento del PNB), y la brecha entre la demanda solvente de la población y el suministro de bienes se amplió de manera notable...; con lo que la tasa de inflación se elevó a 9 por ciento anual... Durante los próximos años la atención se concentrará en atender dos cuestiones interrelacionadas: el rejuvenecimiento financiero de la economía y la elevación del nivel de vida de la gente, sobre todo de los estratos más pobres.

"A fin de equilibrar los ingresos y los gastos presupuestarios, así como los del mercado dé consumo, se intentan reducir significativamente las inversiones de capital en la producción, los gastos de defensa, los subsidios estatales para las empresas no redituables y el gasto para sostener el aparato administrativo del Estado. Asimismo, se han dado pasos importantes para aumentar el abasto de bienes de consumo...

"Muchos economistas consideran que las medidas indicadas por el gobierno son insuficientes y que se requieren incentivos adicionales para aumentar la cantidad de bienes disponibles. Entre sus recomendaciones se encuentran elevar la importación de bienes de inversión de otros países, a costa de reducir el volumen de otras compras, y captar recursos mediante emisión de títulos estatales y mayores incentivos para el ahorro, a fin de canalizarlos a la inversión. También se propone el uso más amplio de cheques y tarjetas de crédito en el comercio al menudeo, y otras medidas que 
faciliten el intercambio...

"Se prevé continuar con el programa de conversión en gran escala de las industrias de defensa, aumentando la participación del producto civil, sobre todo los bienes de consumo y de equipo para la manufactura de éstos, en las empresas que hoy integran el complejo de defensa del país... Los preparativos para el tránsito hacia nuevas formas de manejo de la economía comenzaron apenas en 1988-1989. Tomó mucho tiempo, alrededor de tres años, concebir el perfil de un nuevo sistema administrativo integral y esbozar la legislación para el cambio hacia un nuevo sistema... Un gran paso en este sentido es la formación de un mercado desarrollado.

"Una tarea de gran importancia es crear el mercado de recursos y de bienes del productor. En buena medida, las autoridades centrales siguen asignando esos recursos y bienes mediante el sistema de suministro de materiales y maquinaria. A fin de constituir un mercado al mayoreo de los bienes que requieren las empresas productoras es necesario ajustar las existencias de dinero que poseen las empresas, las organizaciones y el Estado, con la cantidad real de bienes en circulación. Existe en la actualidad un cuantioso excedente monetario, debido al enorme déficit del presupuesto del Estado (alrededor del 13 por ciento del PNB) y al exceso de crédito... Al mismo tiempo se reformará el sistema bancario: en lugar de los tres bancos oficiales, que funcionaban con presupuesto estatal y concedían créditos con fondos del Estado, se han establecido alrededor de 100 instituciones especializadas: bancos comerciales, cooperativos y de innovación. Se pretende que todas ellas sean autofinanciables. Asimismo se prepara una ley que hará del banco de Estado de la URSS el banco de bancos, para que, como institución central, regule la política crediticia y las tasas de interés".

(Tomado del informe de Gorbachov: "El nuevo mecanismo económico supone transformar radicalmente el sistema de abastecimiento técnicomaterial a las empresas: el paso del abastecimiento centralizado al comercio al por mayor de los medios de producción. Hay que garantizar a las empresas la posibilidad de comprar, con el dinero por ellas ganado, todo cuanto se necesita para fabricar la producción, realizar la construcción y la reconstrucción, resolver los problemas sociales... Importantes tareas se han de afrontar en materia de finanzas, crédito y circulación monetaria. Sin ello será imposible crear un nuevo mecanismo económico. El problema principal en este ámbito es el desfase entre el movimiento de recursos financieros, crediticios, monetarios y el de valores materiales, así como la denominada sobreliquidez. El rublo de hoy no cumple en plena medida su función de medio de control financiero de la economía. Es evidente que el sistema financiero del país se ha vuelto obsoleto. No estimula la eficiencia y, en muchos casos busca objetivos momentáneos, meramente fiscales. El crédito ha perdido buena parte de su fuerza; los límites que lo separan de la subvención están desdibujados...", pp. 46 y 52.)

"Otro elemento importante para crear un mercado de bienes del productor es cambiar el modo en que se fijan los precios, como parte de la reforma general en esta materia. En la medida de lo posible, el nivel general de precios internos y las relaciones entre ellos deben vincularse con los del mercado internacional. Además, es necesrio disminuir drásticamente la parte de los precios que se establezca mediante la planeación central y limitarla a unos cuantos grupos de productos claves... También habrá reformas de los precios al por mayor de los bienes de consumo, pero se postergarán unos tres años en vista de las actuales escaseces en el comercio al menudeo...".

(Del Informe de Gorbachov: "Como esencial parte integrante de la reestructuración económica se presenta la reforma radical del sistema de fijación de precios. Sin esta reforma es imposible pasar el nuevo mecanismo. El precio debe desempeffar un papel estimulador en cuanto a mejorar la calidad del producto, a impulsar el progreso técnico-científico y a racionalizar todo el sistema de distribución y de consumo. En este sentido, deben aplicarse nuevos enfoques, adecuados a la actual etapa de desarrollo"..., p. 49.)

"Además del mercado de bienes y servicios se está creando, como parte de la reforma bancariacrediticia, un mercado de capital en relación di- 
recta con el mercado de valores y la emisión de acciones y bonos. Algunas empresas y cooperativas han comenzado a emitir acciones. Esta práctica todavía no es general por falta de una legislación adecuada, que apenas se está preparando. Muchos economistas consideran que la emisión y tenencia de acciones pueden ser un medio excelente para el desarrollo de muchas cooperativas y empresas manejadas por el Estado. Diversas empresas y organizaciones emitirán acciones para asegurar el flujo de capital de una industria hacia la otra, y también para que estén a disposición de particulares, sobre todo de quienes trabajan en la empresa correspondiente y se interesen por tanto en participar en las ganancias y en el manejo de ella.

"El Estado y sus organizaciones desempeñarán un papel crucial en el futuro mercado socialista. La Ley de Empresas Estatales estableció un sistema de pedidos oficiales, que en 1989 abarca cerca de 45 por ciento de la producción industrial y casi la totalidad de las materias primas, así como el 20-30 por ciento de las manufacturas. En el futuro, a medida que se fortalezca el mercado y más empresas logren una genuina independencia económica, los pedidos estatales disminuirán a no más del 30 por ciento del volumen de la producción. Con fines comparativos, cabe señalar que en Estados Unidos las compras del gobiemo representan el 22 por ciento del PNB.

"Se comprende que el papel del plan en el sistema socialista seguirá siendo esencial. Sin embargo, a diferencia del pasado, se concentrará en tareas estratégicas de largo plazo y no cubrirá todos los aspectos del desarrollo económico, ni incluirá detalles y puntos menores. Aún más importante es que el plan no se aplicará de manera coercitiva mediante órdenes administrativas, situación en la que las empresas se hallaban atadas, sino mediante instrumentos e incentivos económicos que les darán un amplio margen de iniciativa e independencia.

"Estos procesos se extenderán naturalmente a la esfera de las relaciones económicas externas. Se ha eliminado el monopolio que el Ministerio de Comercio Exterior de la URSS ejercía en las operaciones de importación y exportación con com- pañias extranjeras... Hoy día el rublo no es convertible, por lo que el mecanismo económico para las relaciones con el exterior está en gran medida divorciado del sistema interno. Las empresas tienen varias cuentas en diferentes bancos, unas en rublos, otras en divisas en el banco para las relaciones económicas externas. En la práctica, el rublo no se puede cambiar por monedas extranjeras... Desde luego, cuando se haya transitado de la convertibilidad interna a la total, una vez que el rublo se cotice en los mercados monetarios de otros países, la moneda soviética tendrá una valoración económica más adecuada. Con ello, la URSS dará un gran paso adelante en su participación en la economía mundial, sobre todo en los sistemas monetario y financiero internacionales. La libre convertibilidad del rublo es una de las principales metas de la reforma económica soviética. No se ignora cuán difícil y complicado resultará... Una condición importante para ello es que la Unión Soviética sea más eficiente en sus relaciones económicas externas y, sobre todo, que sus bienes se vuelvan más competitivos en el mercado internacional.

"En el proceso de reestructuración de las relaciones económicas con el exterior se han comenzado a formar empresas conjuntas con compañías extranjeras, lo cual estaba prohibido en territorio soviético. Al principio se pusieron numerosas restricciones para su establecimiento, y durante dos años sólo se crearon unas 200 ... Hoy, un ciudadano extranjero puede ocupar las posiciones directivas más altas de una empresa conjunta y hay mayor libertad para escoger y pagar al personal, por ejemplo... Pasando cierto tiempo -quizás a finales del siguiente plan quinquenal - será posible incluir a las empresas conjuntas en el mercado interno de divisas y establecer, cuando sea necesario, un rublo convertible al menos parcialmente. La conveniencia de establecer en el país zonas de libre comercio para las empresas es una cuestión zanjada, al menos en principio...".

(Del Informe de Gorbachov: "En el mundo actual ningún Estado puede considerarse económicamente aislado de los demás estados. Nuestro país no es una excepción: la economía soviética forma parte de la economía mundial. Las rela- 
ciones comerciales y monetario-financieras internacionales, los recientes cambios científico-técnicos inciden de una $\mathbf{u}$ otra manera, pero inevitablemente, en la economía nacional... Dicho en otros términos, teniendo presente la considerable participación de la URSS en la economía mundial, la reforma de la economía soviética contribuirá a desarrollar una amplia cooperación internacional y, por tanto, a sanear las relaciones económicas internacionales".)

"En la compleja gama de problemas relacionados con la participación de la URSS en la economía mundial, destaca el de una integración mayor con el sistema financiero internacional. La plena participación del país en la economía mundial presupone una política financiera externa más activa y multilateral. En particular, será preciso adherirse a diversos organismos financieros internacionales, negociar en el mercado mundial de valores, establecer sucursales de los bancos soviéticos en el exterior y otorgar a diversas instituciones bancarias el derecho de conducir operaciones financieras internacionales. La Unión Soviética debe prestar y pedir prestado. En pocas palabras, debe tomar el lugar que le corresponde en el sistema financiero internacional... La transición hacia una economía abierta, los contactos directos de las empresas y las organizaciones con compañías extranjeras, así como el establecimiento de empresas conjuntas en el territorio de la URSS y más adelante en otros países, son tendencias que influirán cada vez más en la calidad y competitividad de los productos soviéticos... Se están abriendo escuelas de administración en las que participan especialistas occidentales y cada vez más soviéticos se capacitan y reciben entrenamiento práctico en occidente. La importancia de esta tendencia, que apenas empieza a ganar fuerza, difícilmente se puede exagerar, ya que la mejor inversión es la que se hace en el hombre, en el mejoramiento de sus conocimientos y habilidades...

"Enorme importancia se concede en la URSS a concertar un acuerdo de gran alcance con la CEE... La URSS tiene una política de intensa cooperación con el mundo en desarrollo, pero la participación de éste en el comercio exterior es aún pequeña (poco más del 11 por ciento), si bien está creciendo aunque muy lentamente. El país está interesado también en desarrollar más las relaciones económicas con el tercer mundo. $\mathbf{Y}$ aquí surge el tema de la posición soviética frente al problema de la deuda externa de las naciones en desarrollo. La URSS, al igual que otros miembros de la comunidad internacional, está preocupada por el ensanchamiento de la brecha entre los países desarrollados y la mayoría en desarrollo, que cada día se vuelve más amenazadora en escala mundial. La buena marcha de la economía mundial exige una solución de este gravísimo problema. En su discurso de diciembre de 1988 en la ONU, Mijail Gorbachov subrayó la necesidad de enfrentarlo como un asunto que concieme a todo el mundo..."42.

Hasta aquí el extracto de los lineamientos de la reestructuración económica en la URSS, presentado por A. Aganbegian, afiliado al grupo de Unión Democrática. Otros países como Polonia, Hungria, Checoslovaquia llevan adelante sus respectivas reformas. También China quiere combinar una sí-reforma económica con una no-reforma política...

Aquí terminaria, de momento, este recorrido sobre las memorias de los "socialismo reales". La tarea no es tiempo perdido si lo que se busca es descubrir la verdad y el engaño. Por ello, es de alabar el contenido y la letra de Perestroika, que no es un himno al Partido Comunista, sino un panegírico a esos pueblos que tanto han trabajado y sufrido por unos ideales sociales. Los llamados socialismos reales, es decir, sus dirigencias políticas, han fracasado víctimas de su propio engaño. En este proceso de autocrítica, tan rudo y sincero, se critican los mecanismos políticos de control del poder, pero se reviven siempre los ideales sociales a nivel de la humanidad. Ahora y ante otros movimientos sociales, otras modalidades de socialismo lo siguen defendiendo y aplicando; por ello, no se puede hablar de que el socialismo está muerto y sepultado. Los ideales sociales deben estar presentes en el plan y en el mercado.

La autocrítica la debemos asumir también nosotros, sea cualquiera el punto del espectro político en que estemos situados. Algunos dicen 
que la historia avanza por oposición de contrarios; pero todo este comentario nos enseña que en la hechura de la historia mucho influyen los contrarios a la oposición: los que habiendo absorbido y detentado el poder, por cualquier medio, son contrarios a toda oposición. Los unos utilizarán el escudo del plan, los otros el escudo del mercado, y normalmente, los dos la espada de la fuerza militar. Al trasladar muchos de estos testimonios, críticas y confesiones, era posible pensar que se decían del lado de allá y del lado de acá del Océano Atlántico. Por eso no ha sido tiempo perdido hacer estas memorias, porque la autocrítica también nos es útil y aplicada a nosotros. Además, unirse a la autocrítica de un modelo concreto no significa estar de acuerdo y asentado en el otro extremo del péndulo.

\section{Notas}

1. Academia de Ciencias de la URSS. Problemas centrales de la historia rusa y soviética. Nuevos estudios y enfoques. "Serie: historia de la URSS". Moscú: Editorial Nauka, 1990.

2. F.M.I., World-Bank, O.E.C.D., European-Bank for reconstruction and development, The Economy of The URSS: Summary and Recomendations. Washington, D.C., 1991.

3. Ota Sik. Sabre la economía checoslovaca. Un nuevo modelo de socialismo. Madrid: Ariel, 1971. J. Selucky. El modelo checoslovaco de socialismo. Madrid: Alianza, 1969. J. Hajeck. Dix ans aprés: Prague 1818-1978. París: E. Seuil, 1978.

4. K. Maidanik. La revolución de las esperanzas. Managua, 1988.

5. E. Plimak. Problemas centrales de la historia rusa y soviética. Opus cit., p. 121.

6. G. D. H. Cole. Historia del pensamiento socialista: Comunismo y socialdemocracia V, VI. México: F.C.E., p. 120.

7. E. Plimak, op. cit., pp. 126-128.

8. Francisco Javier Ibisate. Revista Realidad Económico-Social, enero, 1990; pp. 17ss.

9. R. Menvédev. Let History Jugde: The Origins and Consecuences of Stalinism. N. Y.: Columbia Press U., 1989.

10. R. Menvédev, op. cit., capítulos $3,4,5,6,7,8,11$ y 13.

11. W. Brus. El funcionamiento de la economía socia lista. Oikos, 1968, pp. 64ss.
12. W. Brus, op. cir., pp. 66-78. E. Preobranzhensky. La nueva economía. México: Editorial ERA, Prólogo de E. Mandel, 1971.

13. R. Menvédev, op. cir., pp. 129-130.

14. Mesa redonda, op. cit., pp. 147-152.

15. M. Gorbachov. Tareas del partido en la reforma radical de la administración económica. Moscú: Ed. Novosti, 1987.

16. Mesa redonda, op. cit., pp. 130-131.

17. Mesa redonda, op. cit., p. 122ss.

18. Foro de Barcelona La perestroika: ia dónde la Unión Soviética? Madrid: Editorial Pablo Iglesias, 1989.

19. Francisco Javier Ibisate, "La intolerancia del partido único". Realidad Económico Social, 1990, 13: 16-17 y 33-41.

20. Gorbachov. Perestroika, pp. 20-25.

21. Ota Sik. Argumentos para una tercera vía: ni capitalismo, ni comunismo soviético. Barcelona: Ed. DOPESA, 1975, p. 141.

22. Ota Sik. For a Human Economic Demacracy. N.Y.: Preager, 1985, pp. 305-318.

23. Foro de Barcelona, op. cit., pp. 7-9.

24. Ibid., pp. 17-19.

25. G. D. H. Cole, op. cit., pp. 350-351.

26. Realidad Económico Social, 1990, 13: pp. 34-35.

27. Ibid., pp. 28-43.

28. Juan Pablo II. Centesimus Annus, 1991, № 42.

29. B. B. Seligman. Principales corrientes de la ciencia económica moderna. Barcelona: Oikos, 1966, pp. 92-100.

30. M. Lavigne. Les économies socialistes soviétique et européenes. París: 1979, pp. 14-15 y 425.

31. Las citas del Foro de La Sorbona están tomadas de El País, 22 de marzo de 1990, "Temas de nuestra época", pp. 1-12.

32. Y. Afasaniev, "Perestroika: la única salida", Blanco y Negro, 30 de septiembre de 1990, pp. 6-7.

33. A. Grachov, "¿Sigue siendo la URSS una gran potencia?", El País, 17 de diciembre de 1990, p. 50.

33. Ibid.

35. G. De la Dehhesa, "La curva de Gorbachov", El País, 4 de junio de 1991, p. 58.

36. M. Lavigne, op. cit., p. 17.

37. Y. Ligachov, "Hemos sacrificado demasiado por la casa común europea", El País, 25 de noviembre de 1990, pp. 6-7.

38. Perestroika, pp. 18-20.

39. Gunder Frank, "El desarrollo de la crisis y la crisis de desarrollo". Comercio Exterior, 1980, 3: pp. 239.

40. P. Sweezy y Ch. Bettelheim. Algunos problemas 
actuales del socialismo. México: Ed. Siglo XXI, 1973, pp. 13-16 y 64-65.

41. M. Dobb. El nuevo socialismo. Barcelona: Oikos, 1973, pp. 101-102.
42. A. Aganbegian A., "La reestructuración de la economía soviética y las relaciones económicas internacionales", Comercio Exterior, mayo de 1990, pp. 421-424. 